\title{
MARKET STRUCTURE AND THE GEOGRAPHIC DISTRIBUTION OF BRAND SHARES IN CONSUMER PACKAGE GOODS INDUSTRIES*
}

\author{
Bart J. Bronnenberg ${ }^{\dagger} \quad$ Sanjay K. Dhar ${ }^{\ddagger} \quad$ Jean-Pierre Dubé ${ }^{\ddagger}$
}

July 18, 2006

\begin{abstract}
We describe industrial market structure using a unique database spanning 31 consumer package goods (CPG) industries, 39 months, and the 50 largest US metropolitan markets. We organize our description of market structure around the notion that firms can improve brand perceptions through advertising investments, as in Sutton's endogenous sunk cost theory. In the data, observed advertising levels escalate (i.e. larger brands) in larger markets while the number of advertised brands within an industry remains stable. Correspondingly, observed concentration levels in advertising-intensive industries are bounded away from zero irrespective of market size. For two industries, we collect historic order-of-entry data. The geographic distribution of entry is found to account for the levels, rank-orders and covariation in the geographic distribution of brand shares, perceived brand qualities and advertising effort. Interestingly, alternative potential sources of geographic asymmetry on both the supply and demand sides do not mimic the geographic patterns of shares. In general, our findings highlight several striking persistent geographic patterns in the industrial market structures of CPG industries.
\end{abstract}

JEL classification: L11, L66, M30, M37, R12

\section{Introduction}

Consumer packaged goods (CPG) industries provide a unique opportunity to study the formation of industrial market structure in a context of considerable economic importance. The overall food industry reached roughly $\$ 950$ billion in 2004, with almost $50 \%$ deriving from retail sales ${ }^{1}$.

\footnotetext{
${ }^{*}$ We are very grateful to Emek Basker, Tim Conley, Matt Gentzkow, Avi Goldfarb, Jonathan Levin, Sanjay Sood, Raphael Thomadsen and Florian Zettelmeyer for insightful comments and discussions. We also thank seminar participants at Cornell University, Duke University, Harvard, MIT, New York University, the University of Chicago, the Yale SOM, the 2004 Choice Symposium in Estes Park, Colorado, the 2004 Marketing Camp at Leuven, the 2005 NBER Winter I.O. meetings, the 2005 CRES conference at Olin and the 2005 SICS conference at Berkeley for valuable feedback and helpful suggestions. We are also grateful to Ed Lebar of Young \& Rubicam Brands for providing us with the BAV data, to Jeff Hermann of Nielsen Media Research for the historical advertising data and to the librarians of the National Museum of American History for the archival data on coffee. We acknowledge the research assistance of Avtar Bhatoey with the collection of the local brand entry data. The authors are also grateful for research support from MSI, grant \#4-1301. Dhar thanks the Neubauer faculty fund for research support. Dubé acknowledges the support of the Kilts Center for Marketing.

${ }^{\dagger}$ UCLA Anderson Graduate School of Management, University of California, Los Angeles

${ }^{\ddagger}$ Graduate School of Business, University of Chicago

1 "Food Retailing in the 21st Century - Riding a Consumer Revolution," The Food Marketing Institute, http://www.fmi.org/media/bg/FoodRetailing.pdf
} 
As a data resource, information on most of the marketing investments and the resulting brand sales performance are available for a wide cross-section of industries and local US markets. These data offer an opportunity to analyze industry-level aspects of market structure, such as the size distribution of CPG brands across geographic markets. The richness of the data also permit a more micro analysis of the composition of an industry, such as patterns in market leadership and the relative performance of different brands. The limited degree of physical product differentiation in many CPG industries facilitates the attribution of market structure to marketing investments. We use such data to investigate whether, across industries, larger markets tend to exhibit more brands or better brands (i.e. brands with higher perceived quality), where the latter might be the outcome of larger investments in marketing. We also study whether the same brand tends to dominate an industry across US markets and, more generally, whether we observe the same market structure in an industry across geographic areas. This cross-industry analysis of market structure across US geographic markets generates a number of novel stylized facts that offer ample opportunity for future research.

Recent literature in industrial organization provides guidance in establishing generalizable cross-industry empirical predictions regarding industrial market structure. As in Sutton (1991), we organize our description of market structure around an industry's advertising intensity. Advertising is assumed to increase the perceived quality of a brand. If advertising consists of a fixed and sunk investment, Sutton's theory predicts a competitive escalation in advertising levels, and hence perceived brand quality levels, in larger markets. The economies of scale in advertising limit the extent of entry and, consequently, bound the level of concentration away from zero even in very large markets. This prediction embodies the essence of the endogenous sunk costs (ESC) theory of market structure (Shaked and Sutton 1983, 1987, and Sutton 1991, 2003). In an alternative model where advertising consists primarily of variable costs, it will not generate economies of scale in large markets and hence one would expect a competitive escalation in entry leading to a limiting concentration of zero (Berry and Waldfogel 2003). Similarly, in a model with only a constant sunk entry cost (e.g. a model where set-up costs do not involve advertising), economies of scale become less important in very large markets, allowing for escalation in entry and low concentration. These basic theories of industry-level market structure generate several testable predictions across industries and geographic markets based on patterns in advertising, the number of competitors and concentration.

For stylized versions of the ESC model, one can extend the theory to accommodate sequential entry. This extension introduces an order-of-entry effect (Lehmann-Grube 1997). ESC ensures that at least one firm secures a non-trivial market share. The order of entry can, for some specifications, predict which firm secures the share leadership position. While the entry-related predictions are less robust to model specification, it is interesting to study empirically whether 
order-of-entry covaries with market structure in the data. In particular, one can examine whether history influences the relative performance of brands within an industry across geographic areas.

We collect a comprehensive database for the purpose of describing industrial market structure in CPG industries. The data consist of longitudinal marketing data for all the brands from 31 CPG industries, covering 39 months in the 50 largest city market areas, as designated by AC Nielsen. Unlike previous work using international markets, our narrower focus on markets within the US has the advantage of ensuring more consistency in the physical characteristics of a given brand across markets. For a subset of 23 geographic markets, we match contemporaneous as well as historic advertising levels from several years prior to the sample. These are measures of media advertising which, in CPG industries, are generally used for branding purposes. The advertising data allow us to distinguish between industries based on the extent to which they invest in branding to build better brand quality perceptions. In addition to advertising effort, we also observe advertising prices by market, allowing us to control for differences in the cost of media advertising across markets. Since the data contain all the brands available in a market within each category, we can conduct a comprehensive cross-industry analysis of the relationship between market size and the distribution of advertised versus non-advertised brands. We also use novel survey-based data from Young and Rubicam Brands with information on geographic variation in brand quality perceptions and brand attitudes. Finally, for two of the industries, we supplement the data with information on entry (the year a brand entered a local market).

The data exhibit industry-level geographic patterns that are consistent with the predictions of ESC theory and which collectively document several novel stylized facts about CPG industries and brands. The typical industry/market is concentrated. However, within an industry, the level of concentration varies considerably across markets and, in some cases, reaches very low levels. Also consistent with the theory, advertising levels escalate in larger markets. Correspondingly, the number of advertised brands does not increase in larger markets; although the number of nonadvertised "fringe" brands increases with market size. Partitioning the industries into advertising intense and non-advertising intense groups, we find for the former that concentration is bounded away from zero irrespective of market size. For the latter, concentration falls towards zero in larger markets. These patterns are consistent with the ESC notion that advertising creates economies of scale that persist even in very large markets. Thus, we observe bigger brands (i.e., more heavily advertised) rather than more brands in larger markets. The lack of fragmentation rules out alternative models such as pure horizontal differentiation, on the demand side, and advertising as a relatively variable cost, on the supply side.

Having established the result regarding market structure at the industry-level, we next look at the role of historic entry and patterns in the composition of an industry's market structure. We generally observe striking amounts of dispersion in brand shares across markets, at the individual 
brand level, and in the rank-order of brand shares across markets, at the industry level. Hence, the identity of the brand that is a market share leader in an industry varies across geographic areas. The main idea is to test whether early entrants secure the share-leadership position. The empirical identification of a first-mover effect requires a distinction between the impact of a first-mover ("state dependence") and differences in the relative marketing competencies of firms ("heterogeneity"), a problem analogous to the incidental parameters problem (Heckman 1981). The extant literature on the "pioneering advantage" has documented early-mover effects across a wide range of industries. Typically, this literature uses a single time-series within an industry (see Golder and Tellis 1993 for a historical analysis, and Kalyanaram, Robinson and Urban 1995 for a detailed literature survey). Our identification strategy uses the observed variation in the identities of the first-movers across markets within a given industry ${ }^{2}$.

In the two industries for which we observe historic entry, the historic order-of-entry appears to be a good predictor of a brand's share levels across markets. We also use the brand quality measures to show a comparable correlation between entry and perceived quality levels across areas. Finally, historic entry tends to correlate with a brand's share of advertising spending across markets. These findings are consistent with versions of the ESC model under sequential entry in which an early entrant invests more aggressively in advertising than subsequent entrants, thereby enabling the former to establish higher perceived quality brands. The relationship between historic entry and brand share are consistent with the aforementioned literature on pioneering advantage. However, our analysis makes several novel contributions in this area, including the use of brand quality perceptions and advertising intensity as dependent variables. Furthermore, the share data are also found to be highly spatially dependent in all 31 industries. In coffee and mayonnaise, the geographic distribution of order-of-entry accounts for most of this spatial dependence. Hence, even though the entry effect can only be described in two industries, it appears to be connected with geographic patterns that generalize across all 31 industries. To the best of our knowledge, we are the first to link historic entry patterns to the spatial variance of market shares across geographic markets.

We also investigate several alternative economic explanations for the geographic patterns in market shares. By establishing that spatial dependence accounts for most of the geographic variance in shares, we can test entry against alternative sources of firm asymmetries simply by looking at their spatial densities. We find that strategic asymmetries such as the relative proximity

\footnotetext{
${ }^{2}$ A similar approach is used in Brown and Lattin (1994) in their case study of an industry that launched in the late 1980s. Although they observe the same first entrant in 37 out of 40 markets analyzed. We explicitly use industries with their origins in the late 19th and early 20th centuries to ensure that the brand roll-outs were not part of a nationally-coordinated launch plan. The very gradual and uncoordinated geographic rollout of our brands is critical for our assumption of independent play of the "game" across markets. In addition, the use of modern-day rollout data introduces an endogeneity bias in the sense that a strategic firm may select the strongest markets first. In contrast, market selection in our national entry patterns was limited by very high distribution costs.
} 
to a production facility or the potential formation of a relationship with a national retail chain do not appear to account for asymmetries in market shares. Surprisingly, we find no systematic geographic correlation between shares and promotions. This marketing variable is found instead to co-move with shares over time, which accounts for a relatively small component of the total variance in shares.

This collection of results contributes to a growing empirical literature testing game-theoretic models of industrial market structure formation. Our work follows an approach pioneered by Sutton (1991, 2003), who provided several detailed case studies testing the implications of sunk costs on market structures in the food industry across international markets. ${ }^{3}$ The theory has subsequently been used to describe market structures for US manufacturing industries (Robinson and Chiang 1996), and recently for several industry case studies including the supermarket industry (Ellickson 2004a, 2004b), newspapers and restaurants (Berry and Waldfogel 2003), and banking (Dick 2004, Cohen and Mazzeo 2004). Our work is related to the literature documenting the relationship between market size, entry and the size-distribution of firms (e.g. Bresnahan and Reiss 1991, Berry 1992 and Campbell and Hopenhayn 2004). Insofar as we observe more advertising in larger markets, our work is also related to the literature studying the geographic Silicon-Valley type agglomeration of firms (e.g. Krugman 1991, Ellison and Glaeser 1997, 1999).

The remainder of this paper is organized as follows. Section one outlines the theory and some comparative static predictions from a model of ESC, including the role of sequential entry. In section two, we describe our data. In section three, we test the industry-level predictions of basic ESC theory. In section four, we look within-industry and test for a relationship between historic order-of-entry and relative brand shares. Section four also explores several alternative explanations for these patterns. Section five concludes.

\section{Endogenous Sunk Costs Theory}

\section{A Basic Theory and Industry Level Predictions}

In this section, we discuss the empirical predictions that arise from a basic model of endogenous sunk costs. Following the discussion of the model, we clarify which forms of advertising contribute to the creation of brands in CPG industries and why these investments may indeed be characterized as fixed and sunk.

The basic results are based on the Perfect Equilibrium of a three-stage game. In the first stage, firms decide whether or not to enter an industry which involves paying a constant sunk set-up cost. In the second stage, firms strategically choose their brand's positioning. In a model with advertising, this decision would involve choosing a sunk investment level in advertising for

\footnotetext{
${ }^{3} \mathrm{~A}$ related literature uses structural models to study market structure when crucial market outcome data such as prices and sales are unavailable (Bresnahan and Reiss 1991, Berry 1992).
} 
the purposes of increasing the perceived quality of the brand. In a model without advertising, this stage might simply involve firms costlessly choosing their brands' positions in a horizontallydifferentiated product space. In the third and final stage, firms compete on prices (Bertrand Nash equilibrium).

In the following discussion, we summarize the details of the model and the results proved formally in Shaked and Sutton (1987). We provide some technical details in Appendix A. Several crucial assumptions are required. First, advertising raises a consumers' willingness-to-pay for a brand. Second, the burden of advertising falls more on fixed than variable costs. This seems like a reasonable assumption for the CPG markets in which advertising decisions are made in advance of realized sales. It is unlikely that advertising spending would have a large influence on marginal (production) costs of a branded good. ${ }^{4}$ In a subsection below, we provide more details about the nature of advertising and the validity of these assumptions for CPG industries. In more general consumer settings, these assumptions may not be innocuous. Berry and Waldfogel (2003) examine the role of this assumption for market structure. In the restaurant industry, where they find that quality is borne mainly in variable costs, they find that the range of observed quality levels rises with market size while market shares fragment with market size. In contrast, for the newspaper industry, where they expect quality to be a fixed cost, they observe average quality rising with market size without fragmentation.

In a purely horizontally-differentiated market, Shaked and Sutton (1987) prove that concentration converges to zero as market size increases. The intuition is that in a model where firms bear only constant fixed entry costs, economies of scale cease to matter in very large markets, which allows for a proliferation in product entry. In a Hotelling model, for example, increasing the mass of consumers along the horizontal continuum leads to a limiting result where the entire continuum is served and all firms earn arbitrarily small shares.

In contrast, as market size increases for industries in which firms can make fixed and sunk investments in quality (i.e. vertical attributes), we do not see an escalation in entry. Instead, we see a competitive escalation in advertising spending to build higher-quality products. The intuition for this result is that advertising creates a form of vertical product differentiation. The highest-quality firm will always be able to garner market share and earn positive economic profits by under-cutting lower quality rivals. The escalation in advertising implies that economies of scale matter even in very large markets and, hence, only a finite number of firms enter even in the limit.

The distinction between the prediction for a model of horizontal versus vertical product differentiation indicates that product differentiation per se is insufficient to explain concentration.

\footnotetext{
${ }^{4}$ The main driving force for CPG private labels and store brands is the fact that one can frequently mimick the national brand physically without the overhead required to build the brand name.
} 
When firms cannot build vertically-differentiated brands (by advertising) we expect markets to fragment as market size grows. In contrast, when firms can invest to build vertically-differentiated brands, we do not expect to see market fragmentation, but rather an escalation in the amount of advertising and the perseverance of a concentrated market structure. These predictions are robust to a very wide class of discrete choice models of demand with horizontal and vertical product differentiation.

Sutton (1991) discusses a hybrid case that arises in markets where consumers may be segmented according to those who derive utility from the vertical attribute (i.e. brand quality) and those who do not. In such a market, it is possible to sustain firms that do invest in the endogenous sunk cost as well as firms that do not. In the limit, these two subsegments of advertised and non-advertised brands diverge to two independent market structures. As market size grows the former set of firms will have a concentration level bounded below. However, concentration for the latter set of firms will converge to zero. In this respect, the theory provides differential predictions for firms that advertise and firms that do not.

The results above generate a basic set of predictions for long-run market structure. In industries characterized by substantial endogenous fixed and sunk investments, such as advertising, we expect concentration to be bounded below even as the size of the market increases in the limit. However, in the absence of these endogenous sunk investments, we would expect concentration to converge to zero as the market size increases in the limit. Finally, if advertising consists of variable rather than fixed costs, we would then expect to see concentration converge to zero in larger markets for advertising intense industries.

\section{B Sequential Entry and Brand Level Predictions}

The model described above assumes that firms play the entry and product positioning stages of the game simultaneously. This assumption may be unrealistic for CPG industries, many of which originated late in the $19^{\text {th }}$ or early in the $20^{\text {th }}$ centuries and whose brands continued to diffuse across markets well into the late $20^{\text {th }}$ century. An interesting corollary in Shaked and Sutton (1987) is that the non-fragmentation results of the previous section continue to hold under sequential entry for a finite number of firms. Hence, in the presence of endogenous sunk costs, at least one firm garners a non-trivial market share under sequential entry, even in very large markets. Of potential interest is whether sequential entry generates a strategic effect and whether an early entrant can secure the share-leadership position. First-mover effects are discussed in Sutton (1991) and in related models (e.g. Lane 1980, Moorthy 1988 and Donnenfeld and Weber 1992). For example, in the context of a simple Tirole model of vertical differentiation and convex fixed costs for quality (i.e. ESC), Lehmann-Grube (1997) shows that a first-mover chooses a higher quality and secures a higher market-share and profits in equilibrium than a subsequent 
entrant. ${ }^{5}$ The first-mover effect is less robust than the concentration results from the previous section as the former hinges on more stylized modeling assumptions. Nevertheless, it is interesting to investigate empirically whether or not the order of entry covaries with market outcomes such as shares and advertising. According to the Lehmann-Grube model, the identities of specific firms and their relative order of entry may be relevant to the observed market structure. The intuition for this finding is that, in a vertical Tirole model, the firm with higher quality generates a higher share and higher profits in equilibrium. With sequential entry, the first entrant picks a higher quality than the second entrant. Specifically, if the order in which firms in a given industry enter markets differs across geographic areas, then the theory predicts geographic differences in the rank-order of shares.

A separate literature in consumer psychology has investigated the role of first-mover effects in controlled experimental settings (Kardes and Kalyanaram 1992, Kardes, Kalyanaram, Chandrashekaran and Dornoff 1993). For comparable products, the evidence suggests that subjects systematically recall the attributes of earlier entrants better and are more likely to choose earlier entrant products in future brand choice scenarios. The logic for these findings is based on learning. An analogous result is derived analytically by Schmalensee (1982). In our analysis, we cannot rule out these types of inherent first-mover effects on consumer behavior. However, since many of our industries have been around since the mid $19^{\text {th }}$ century, it seems unlikely that a firm could sustain such an inherent first-mover advantage for over one hundred years without some additional strategic difference in its behavior relative to its competitors.

At the brand level, this discussion leads to some support for a prediction that historic order of entry influences both share levels and the rank order of shares in a market. In addition, the order of entry may influence the relative intensity of advertising by competing firms and the degree of perceived quality they create for their brands.

\section{Advertising as an Endogenous Sunk Cost in CPG Industries}

We now briefly discuss the role of brand advertising via television media, the investment we attribute to the ESC model above. We also discuss trade promotions and R\&D, two other candidate investments that we do not believe lead to the market structure patterns observed in the CPG data.

For the purposes of building brand perceptions and boosting consumer willingness-to-pay for brands, CPG firms typically use media advertising. Media advertising targets consumers directly via conventional media for the purposes of branding. For the food industries in this paper, media

\footnotetext{
${ }^{5}$ Doraszelski and Markovitch (2004) show that a first-mover advantage can also persist in a more sophisticated dynamic game where firms invest in advertising every period to sustain a depreciating stock of goodwill. Firm asymmetries (leading to share asymmetries) in the initial goodwill stocks can be shown to persist via asymmetric advertising investment strategies in the long-run.
} 
advertising consists primarily of spot and local cable television. Based on discussions with industry experts, we learned that CPG firms strategically set their advertising plans by geographic area and, as a result, the extent of a brand's advertising on local media varies considerably across geographic markets. ${ }^{6}$ For instance, Miller Brewing has divided the US into 61 sub-markets, each of which has its own "highly individual plan." 7 Since media advertising is determined in advance of sales, it corresponds reasonably well with the fixed and sunk cost structure of the theory in the previous subsections. In our analysis below, we use measures of media advertising to capture a firm's advertising effort.

There are several reasons for which we do not believe promotional spending would lead to the same impact on market structure as brand advertising. Promotional investments by CPG manufacturers consist of funds allocated to "the trade" (i.e. retailers) primarily for the purposes of passing price-cuts to consumers (Blattberg and Neslin 1991). A recent Nielsen survey of manufacturers indicates promotional spending primarily as a means to increase volume. ${ }^{8}$ Blattberg and Neslin (1991) explain that there is some evidence that promotions may weaken brand attitude and, hence, could possibly lower consumer willingness-to-pay. Finally, the cost structure of promotions is primarily variable since the total costs of price-cuts vary with the levels of sales. As discussed in Berry and Waldfogel (2003), this type of cost structure would lead to fragmentation as opposed to concentration in very large markets.

Finally, we also find it unlikely that R\&D investments would influence market structure in CPG industries. Sutton (1991) referred to both advertising and R\&D as general potential sources of endogenous sunk costs. However, Andras and Srinivasan (2003) estimate that advertising intensity for consumer goods averages $5.6 \%$ of sales revenue, while R\&D intensity is $0.7 \%$ of sales revenue. Hence, we focus our analysis on advertising.

\section{Brand Advertising and Consumer Willingness-to-Pay}

We now provide evidence that advertising has been found to increase consumer perceptions of brand quality and to raise their willingness-to-pay, similar to a model of vertical differentiation. For the purposes of describing market structure, it may not be necessary to qualify advertising as a vertical product attribute per se (e.g. such as a car's horsepower or a computer's processor speed). It suffices to assume advertising increases consumer willingness-to-pay. Nevertheless, practitioners believe that spending more money on "more and better advertising" will increase brand sales (Advertising Age 1994).

\footnotetext{
${ }^{6}$ The authors spoke with several industry experts from advertising agencies, such as Millward Brown and JWT, as well as from CPG marketing divisions, such as Kraft and Unilever.

${ }^{7}$ See "National Brand, Local Branding" at http://www.sabmiller.com/SABMiller.

8 "Summary: 2003 Trade Promotion Practices", Consumer Insight, Vol. 6(2), summer 2004, 28-34. http://www2.acnielsen.com/pubs/documents/2004_q3_ci.pdf
} 
Many examples exist in the context of CPGs that demonstrate that branding does influence the perceived quality of a product and correspondingly consumer willingness-to-pay. For example, Keller (2003, p.62) summarizes the results of taste tests using leading beer products such as Budweiser, Miller Lite, Coors and Guinness. In a blind taste test (i.e. where consumers are not aware of the brand identities), the results indicate no perceived differentiation between these products except for Guinness, which is found to be quite different from other beers in the sample. However, in a separate taste test in which consumers know the brand names, the results indicate considerable differentiation between all the brands. In a similar beer study, Allison and Uhl (1964) find that consumers report very different quality rank-orderings on the same sets of products depending on whether or not the brand identities of the products are known. They conclude that, in the case of beer, brands are more relevant for product rankings than physical characteristics. A similar outcome was observed with the 1985 launch of "New Coke," a reformulation of the flavor syrup of Coca-Cola's flagship product. The launch was ultimately labeled the "marketing blunder of the century." Nevertheless, the "New Coke" formula adopted was preferred in blind taste tests by 200,000 consumers. ${ }^{9}$

A related literature demonstrates that brand advertising specifically influences consumer perceptions of brand quality. For instance, consumers exposed to advertising change their brand evaluations favorably towards the advertising brand if they remember information from the advertising (Keller 1987). Similarly, brand awareness increases through advertising (Hoyer and Brown 1990) and repeated brand advertising increases the chance of a brand entering a consumer's consideration set (Nedungadi 1990). The influence of advertising on brand preferences and choice has been shown to persist even in mature product categories (D'Souza and Rao 1995). More specifically, Chakravarti and Janiszewski (2004) find that brand advertising can reduce the price elasticity of demand for specific products in commodities markets, hence isolating the role of brand influence in otherwise homogenous products settings.

\section{Data}

In this section, we describe the data sources used in the analysis. Our primary data source is $\mathrm{AC}$ Nielsen scanner data for 31 CPG industries in the 50 largest AC Nielsen-designated Scantracks ${ }^{10}$ as in Dhar and Hoch (1997). We treat the 50 scantracks as independent markets, as is typically done in practice by large CPG clients who use AC Nielsen scanner data for market analysis and strategic-planning. This practice also has a legal precedent in the merger trial against Coca-Cola and Dr. Pepper, during which the courts ruled that Scantracks represent a legally valid market

\footnotetext{
${ }^{9}$ See story "Coke Lore" at:http://www2.coca-cola.com/heritage/cokelore_newcoke.html.

${ }^{10}$ Each Scantrack covers a designated number of counties, with an average of 30 and a range of 1 to 68 . All markets include central city, suburban and rural areas.
} 
definition (F.T.C. v. Coca-Cola Co., 641 F. Supp. 1128 1986). The geographic areas encompassed by a Scantrack are also roughly consistent with the supermarket distribution regions designated in Ellickson (2004a). Hence, on the supply side, our market definitions correspond to the manner that CPG practitioners define markets when making decisions. Also, on the demand side, it is unlikely that consumers arbitrage differences in brand marketing by traveling to other markets to buy CPG products.

The industries in the database collectively account for roughly $\$ 26$ Billion in annual national revenues. The data are sampled at four-week intervals between June 1992 and May 1995. The CPG industries covered are all large industries representing a wide range of both edible grocery and dairy products. For each market, time period and industry, we observe sales, prices, and promotional activity levels for each of the brands. Brand sales are measured in "equivalent units", which are scaled measures of unit sales provided by AC Nielsen to adjust for different package sizes across brands. We compute a brand's market share by dividing its sales (in equivalent units) by the total sales (in equivalent units) for the industry in a given market and time period. The promotion data break-down the total equivalent unit sales of a brand by the promotional conditions under which they were sold. For our analysis, we construct a promotion variable by computing the fraction of a brand's sales that was sold under any form of in-store promotion including pricecuts and merchandising such as feature advertising and in-aisle displays. In addition to our geographic market (Scantrack) level data, we also have analogous data at the retailer account level for those retailers in each market with local annual revenues exceeding $\$ 2 \mathrm{MM}$. Account level data encompass all stores in the retail chain for the geographic market. There are 67 such retailers in the data, which jointly cover 48 of the 50 Nielsen markets.

In the data, a "brand" encompasses all the stock-keeping units (SKUs) sold baring a given brand name. For instance, in the ground coffee category, the Folgers brand aggregates all the SKUs with the Folgers label which embodies a wide array of can sizes. Similarly, in the yogurt category, the Yoplait brand aggregates all pack sizes and yogurt flavors sold with the Yoplait name on the label. Since brand advertising decisions are made at the brand level and not at the SKU level (i.e. we do not see television advertising for a specific flavor of Yoplait yogurt), we are not concerned about the multi-product nature of the firms in such instances. Even in cases where a CPG conglomerate owns multiple brands, separate management teams typically oversee the marketing of each brand in the portfolio. For instance, Folgers is owned by P\&G - a large brand conglomerate, but has its own separate management team responsible for its marketing. Similarly, according to the company website, Ben \& Jerry's continues to operate "to a large extent independently" and "separately from Unilever's current U.S. ice cream business" even after its acquisition by Unilever. ${ }^{11}$ Hence, we treat each brand in our database as a single product firm.

\footnotetext{
${ }^{11}$ For additional documentation, see http://www.benjerry.com/our_company/press_center/press/join-
} 


\begin{tabular}{lcccc}
\hline brand & $\begin{array}{c}\text { average } \\
\text { local share }\end{array}$ & $\begin{array}{c}\text { average price per } \\
\text { weight equivalent }\end{array}$ & $\begin{array}{c}\text { average \% volume sales } \\
\text { on any promotion }\end{array}$ & $\begin{array}{c}\text { average local } \\
\text { GRPs per month }\end{array}$ \\
\hline Folgers Coffee & $0.302(0.108)^{a}$ & $29.216(2.061)$ & $0.335(0.069)$ & $1043(207)$ \\
Maxwell House Coffee & $0.248(0.121)$ & $29.312(2.304)$ & $0.392(0.078)$ & $795(106)$ \\
Kraft Mayonnaise $_{\text {Unilever Mayonnaise }^{b}}$ & $0.489(0.205)$ & $1.180(0.105)$ & $0.317(0.068)$ & $467(99)$ \\
\hline
\end{tabular}

${ }^{a}$ Deviations across markets in parenthesis

${ }^{b}$ AC Nielsen's weight equivalent units are industry specific. Comparisons across industries are therefore invalid.

Table 1: Descriptive statistics for the main brands

To control for brand advertising, we obtain media advertising data from Nielsen Media Research. The advertising data consist of advertising intensity levels measured in gross rating points $(\text { GRPs })^{12}$ for 23 of the geographic markets. Thus, we observe the advertising GRPs for each brand in each time period for these 23 markets. The distribution of population sizes across these 23 markets is comparable to the distribution across all 50 scantracks. One advantage of using GRP data is that they are normalized measures and can be used to compare advertising intensity across markets of different size. Advertising expenditure levels can still be computed using the list price (by market and quarter) of GRPs reported in the Media Market Guide.

We also consider the impact of historic advertising on current sales using additional AC Nielsen GRP data for the years 1989-1993 for all 31 industries. For each of the 23 markets above with contemporaneous sales and advertising data, we construct a market and brand-specific measure of the historic investment in advertising from 1989 to 1993. Table 1 provides descriptive statistics for the two largest brands in the ground coffee and mayonnaise industries, for which we will also provide details on entry data below. ${ }^{13}$

Table C.I in the Appendix lists the CPG food industries covered, along with each of the geographic markets and retailers in the database. In the analysis below, we report results across the 31 industries. However, for confidentiality reasons, we are unable to name each of these 31 industries. Instead, we use a 9-group classification to identify the industries. For example, the bread industry is included in the "Bread and Bakery" group, the candy industry is included in the "Candy and Gum" group, the butter and cream cheese industries are contained in the "Dairy Products" group, the pizza industry is contained in the "Frozen Entrees/Side Dishes" group, the frozen toppings industry is contained in the "Frozen/Refrigerated Desserts" industry, the juices and coffee industries are contained in the "Non-Alcoholic Beverages" group, the pasta industry is contained in the "Packaged Dry Groceries" group, the mayonnaise and fruit spreads industries are forces.html.

${ }^{12}$ GRPs are the CPG industry standard for measuring media advertising. GRPs are calculated by multiplying reach and frequency. Reach measures the proportion of the target market that has seen the firm's advertising at least once. Frequency measures the average number of times individuals in the target market saw the ad within a purchase cycle.

${ }^{13}$ Comparable descriptive statistics for the remaining 29 categories are available upon request. 
contained in the "Processed Canned/Bottled Foods" group, and dinner sausages are contained in the "Refrigerated Meats" group.

Demographic measures for each market are also obtained from 1993-1995 census data: "Home Value" is the fraction of households in an area owning homes valued over \$150,000; "Elderly" is the fraction of the population in an area older than 55 years; "Education" is the fraction of households in an area with a four-year college degree; and "Ethnic" is the fraction of black and Hispanic households; "Income>50" measures the local fraction of the households with incomes larger than 50K. Additional demographic variables based on census data are collected from the 1994 MarketScope book by Trade Dimensions. These variables include market averages for "Income," "Hispanic," "Household Size," and "Age." Descriptive statistics are available upon request.

To maintain consistency with previous research, we also construct a proxy for the minimumefficient-scale (MES) in each industry to capture the exogenous set-up cost for a firm to enter a market. The MES helps us control for the fact that we expect the potential for escalation in a market to differ across industries with different exogenous set-up costs. As in previous work, we use the MES measure to normalize our measures of market potential so that we can pool our analysis across industries. The proxy is based on data from the 1997 economic census at the industry-level for the manufacturing sector. For each industry, we compute the average value of depreciable assets by dividing the reported "Gross Book Value of Depreciable Assets at Beginning of Year" by the reported "Number of Companies." A summary of these data appear in the Appendix in table C.II. We refer the reader to Sutton (1991, Chapter 4) for a detailed discussion of the empirical issues surrounding the measurement of minimum-efficient-scale in practice. ${ }^{14}$

For a select number of industries, we were able to collect information on the exact geographic location of the manufacturing plant. The plant location provides a measure of cost asymmetries for brands in a market based on the distance from the market to the plant. The plant location data were obtained from interviews with managers, websites and other secondary data sources.

We also obtain measures of perceived brand quality from the 2004 Brand Asset Valuator (BAV), an annual survey conducted by Young and Rubicam (Y\&R), a multinational advertising agency. ${ }^{15}$ The brand value measures constructed by Y\&R are used by many large national consumer goods manufacturers to assess brand performance and brand equity. Consumers are surveyed by $\mathrm{Y} \& \mathrm{R}$ on a large number of yes/no brand characteristics such as whether a particular brand is "high quality," "good value," and "best brand in category." Responses to these ratings are tallied and reported by $\mathrm{Y} \& \mathrm{R}$ as fractions of the sample at the Census subregion level. For each brand and subregion we use the average across the three quality measures as a proxy for

\footnotetext{
${ }^{14}$ Sutton (1991) uses a different proxy for minimum efficient scale based on the median plant output for an industry as a ratio of total industry output.

${ }^{15}$ We also have access to the 1993 BAV survey, which matches our sample period. The 2004 data, however, can be broken down by region which allows us to look across markets.
} 
perceived quality.

Finally, for two of the industries, coffee and mayonnaise, we were able to collect data on the year the brand entered each of the geographic markets. These data were obtained from a large number of sources including historic publications (e.g. Encyclopedia of Brands, the Gale Group, 1993, and Pendergast 1999), the trade press, the manufacturers themselves and the Internet, mainly at manufacturer websites. In addition, we consulted the "Hills Bros Coffee Company" archives at the National Museum of American History, Washington D.C., which contain marketing and sales records from the $19^{\text {th }}$ and early $20^{\text {th }}$ centuries. ${ }^{16}$ In Appendix B, we provide a brief summary of the historic evolution of these two industries. This discussion indicates the slow and differing diffusion of each brand across the US leading to the variation in the identities of first-entrants across markets. In the coffee industry, a potential concern is that we focus only on "surviving" brands as we do not observe those brands that exited the industry prior to our sample (see Golder 2000 for a discussion of potential survivor bias). However, these surviving coffee brands were the first to adopt the vacuum-seal technology that is now an industry standard.

\section{Concentration and Sunk Investments in Advertising}

In this section, we examine whether the main predictions from the ESC framework fit our data. We first discuss the geographic concentration patterns both across and within the 31 industries. Next, we test the basic predictions of the theory by examining the impact of market size on advertising levels, brand proliferation and concentration.

\section{A Concentration in $C P G$ Industries}

The basic theory predicts a lower bound on concentration, which requires at least one firm to garner a non-zero share irrespective of market size. The one-firm concentration ratio, $C_{1}$, emerges as a natural definition of concentration in each industry and geographic market. The 1-firm concentration level, $C_{1}$, is the maximum share across brands in an industry/market. The results below are robust to alternative measure of concentration such as $C_{2}, C_{3}$ or the Herfindal Index.

Table C.III summarizes the concentration levels across industries and markets. For each industry, we compute the within-market mean concentration level and we report the mean, standard deviation, minimum and maximum across markets. On average, all of these industries look fairly concentrated in terms of $C_{1}$. However, within an industry, concentration varies considerably across markets. The average range of concentration levels (difference between minimum and maximum) across industries is 0.41. Hence, on average, the largest market share in an industry varies by as

\footnotetext{
${ }^{16}$ For the mayonnaise industry, entry data were collected mainly through industry contacts and from available histories on company websites and are available only at a regional level. In these instances, an exact entry date would need to be inferred, for example by interpolation based on geographically "close" markets. For this reason, our entry analysis will focus on whether a firm entered first instead of using the exact entry date of a brand.
} 
much as 41 share points across geographic areas. The column reporting the minimum concentration levels reveals that while some industries remain concentrated across all markets (i.e. never fall below 40\%), other industries have markets where concentration falls as low as 0.05 and 0.06 . In summary, we observe strong differences in concentration both across industries and markets. Next, we will examine whether the predictions of ESC theory fit our data and hence account for this variation in concentration across and within industries.

\section{B Advertising Escalation}

If advertising costs are fixed and sunk, as in the ESC model, one would expect to observe an escalation in advertising in larger markets. We define the advertising intensity of an industry by looking at the total advertising investment during and before the sample, 1989 to 1995, scaled by total in-sample industry revenues, 1993 to 1995. The upper and lower quartiles of industry advertising intensity designate the sets of advertising intense versus non-advertising intense industries. ${ }^{17}$ Two measures of market size are used based on the natural logarithm of the total revenues for an industry within a market as well as the natural logarithm of the population of a geographic market. For consistency with the previously literature, the market size (i.e. revenue and population) data are normalized by an industry's minimum efficient scale (MES as defined in the data section) to control for differences across industry in the exogenous fixed set-up costs. In the case of population, the use of a dollar-value normalization is not as intuitive, but we retain this measure to demonstrate robustness of our results to an exogenous definition of market size. The results are qualitatively similar if we disregard the minimum efficient scale measures and proceed as if advertising is the only relevant fixed cost.

Figure 1 illustrates the escalation in advertising for larger markets. The figure plots by market an industry's average advertising expenditure per brand, between 1993 and 1995 against market size measured as the logarithm of revenues over MES. The figure drops the bottom quartile of industries based on advertising intensity as advertising expenditures tend to remain either zero or close to zero across markets in these industries ${ }^{18}$. To measure the market size elasticity of advertising, we regress the logarithm of each industry's average advertising expenditure in a market on the corresponding de-meaned logarithm of market size and industry fixed-effects. We obtain a statistically significant elasticity of roughly one. ${ }^{19}$ We plot the predicted advertising levels in the figure to visualize this escalation. The results indicate that, on average, CPG firms

\footnotetext{
${ }^{17}$ This may not an ideal measure of advertising intensity as it is based on equilibrium outcomes of advertising and sales. A preferable approach would be to use some measure of the marginal effectiveness of advertising in an industry. But, such measures are not readily available.

${ }^{18}$ Although not reported, the same pattern arises if we use GRP levels instead of spending levels. Since advertising prices are higher in larger markets, this confirms that escalation in spending is not merely an artifact of ad costs.

${ }^{19}$ The elasticity is lower, but nevertheless significantly positive if we use GRP levels instead of expenditure levels. Hence, the escalation is not merely an artifact of higher prices in larger markets.
} 


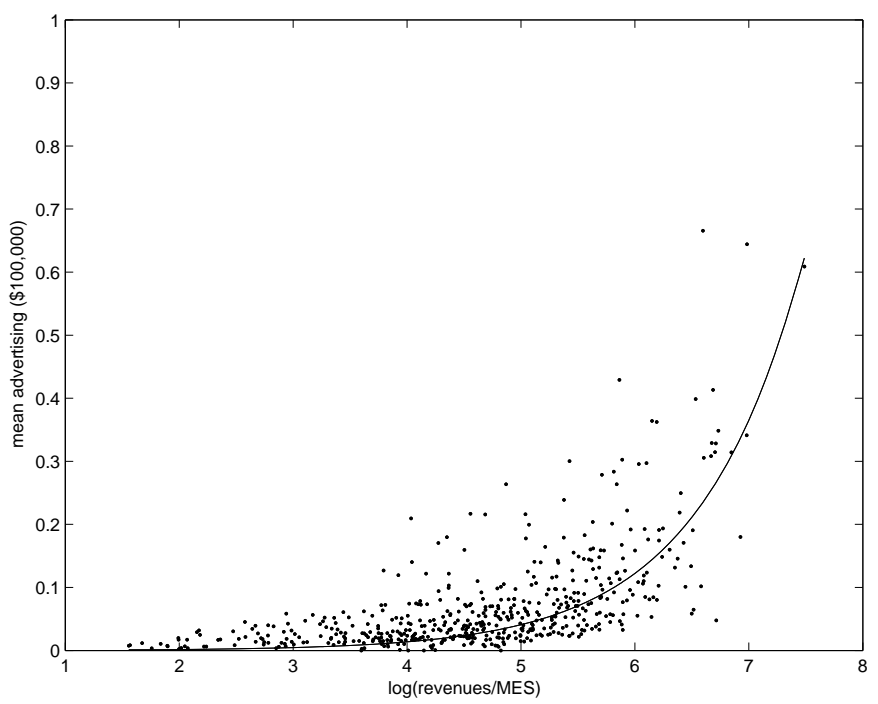

Figure 1: Advertising expenditure per month versus market size excluding the bottom quartile industries based on advertising intensity. The solid line corresponds to the predicted advertising levels from a regression of log-advertising on industry fixed-effects and market size.

advertise more aggressively in larger markets.

\section{Brand Proliferation}

In addition to advertising escalation, ESC theory predicts a non-proliferation in entry. The theory also distinguishes between advertised and non-advertised brands. Specifically, the number of advertised brands does not escalate in larger markets. However, the number of non-advertised "fringe" products does escalate in larger markets. Sutton (1991) provides anecdotal support for this phenomenon in his case studies, but is unable to provide econometric evidence of this phenomenon across industries. In his case study of the supermarket industry, Ellickson (2004b) documents evidence of a similar two-tiered market structure with dominant and fringe firms in the context of supermarkets. He finds that the number of high quality supermarkets remains fixed across markets of varying size, whereas the number of low-quality supermarkets increases in larger markets. A novel aspect of our database is that we are able to document econometric support for this phenomenon across a large cross-section of CPG industries.

Most of the industries exhibit a co-existence of brands that advertise and brands that do not. Table C.V, in the Appendix, reports each industry's average number of brands and market share levels for advertised versus non-advertised brands. We drop the private labels to focus on the proliferation of small local brands; although adding private labels would merely strengthen our results below. Table 2 summarizes these findings. The historic pre-sample advertising levels are used to proxy for investment. Hence, our classification of advertising versus non-advertising 


\begin{tabular}{|r|ccc|ccc|}
\hline & \multicolumn{3}{|c|}{ market share } & \multicolumn{3}{c|}{ number of brands } \\
& mean & min & max & mean & min & max \\
\hline Advertising Brands & 0.27 & 0.06 & 0.68 & 1.39 & 0 & 6.04 \\
Non-Advertising Brands & 0.07 & 0.02 & 0.21 & 8.14 & 1.26 & 19.22 \\
\hline
\end{tabular}

Table 2: Summary of advertising versus non-advertising brands across all 31 industries

brands is based on whether a brand invested in advertising during the years $1989-1993 .{ }^{20} \mathrm{In}$ most industries, we tend to observe considerably more non-advertised brands than advertised brands. Interestingly, the market share of an advertised brand is typically considerably larger than that of a non-advertised brand.

We next test the proliferation prediction by pooling the 31 industries and 23 geographic markets for which advertising is observed. $N_{i m}$ denotes the number of brands that advertise in industry $i$ and market $m$. Since $N_{i m}$ is a count variable, it is assumed to be distributed Poisson with mean $\lambda_{i m}$ where:

$$
\lambda_{i m}=\exp \left(X_{i m} \beta\right)
$$

and $X_{i m}$ contains industry fixed-effects and market sizes (the natural logarithm of either the population to MES ratio or the revenue to MES ratio). We then re-run the regression (1) using the number of unadvertised brands as the dependent variable. The results in Table 3 indicate a statistically insignificant relationship between market size and the number of advertising brands. However, the results do indicate a statistically significant relationship between market size and the number of fringe brands. These findings are robust to both definitions of market size. These results suggest that the number of non-advertising brands increases with market size, while the number of advertising brands does not.

\section{$D$ Advertising and Concentration}

We now test whether the escalation in advertising and non-escalation in the number of brands leads to a corresponding lower bound in concentration as predicted by the theory. Figure 2 contains a scatterplot of observed concentration levels and market size across industries and geographic areas. In accordance with the theory, separate plots are provided for advertising intensive and nonadvertising intensive industries. We define advertising intensity as an industry's total in-sample advertising-to-sales ratio. The advertising versus non-advertising intensive industries consist of

\footnotetext{
${ }^{20}$ For the results reported, we define an advertising brand as one that advertises during each year in our data. A non-advertising brand is defined as one that never advertised during the sample years. Although not reported, all of our results are robust to less conservative definitions that consider brands that "occasionally" advertise (i.e. up to less than half the time) and brands that "occasionally" do not advertise (i.e. less than half the time).
} 


\begin{tabular}{|r|cc|cc|cc|cc|}
\hline & \multicolumn{3}{|c|}{\begin{tabular}{c} 
Number of Brands versus \\
\multicolumn{2}{|c|}{$\log ($ revenues/MES) }
\end{tabular}} & \multicolumn{3}{c|}{$\begin{array}{c}\text { Number of Brands versus } \\
\log (\text { population/MES) }\end{array}$} \\
\hline & \multicolumn{2}{|c|}{ Advertising } & Non-Advertising & Advertising & \multicolumn{2}{c|}{ Non-Advertising } \\
& \multicolumn{2}{|c|}{ Brands } & \multicolumn{2}{|c|}{ Brands } & Brands & \multicolumn{2}{c|}{ Brands } \\
& coefficient & s.e. & coefficient & s.e. & coefficient & s.e. & coefficient & s.e. \\
intercept & 0.89 & 0.14 & 1.58 & 0.09 & 0.95 & 0.13 & 1.70 & 0.09 \\
$\log$ (market size) & 0.07 & 0.06 & 0.11 & 0.02 & 0.02 & 0.06 & 0.10 & 0.03 \\
$\log -$-likelihood & -615.82 & -1577.04 & -616.50 & -1579.82 \\
\hline
\end{tabular}

Table 3: Brand proliferation and market size. The $\log$ (market size) terms are included in deviations from their mean level. Each regression also includes industry fixed-effects.

the respective upper and lower quartile industries based on advertising intensity. For the advertising intensive industries, there is little evidence of a linear correlation between concentration and market size. Even in the largest markets, concentration seldom falls below 20\%. Although not reported, a regression of concentration in each industry/market on market size reveals a statistically significant concave relationship under both market size definitions. ${ }^{21}$ In contrast, there is less evidence of a bound in non-advertising intensive industries where we observe concentration levels as low as 5\%. In this case, a regression of concentration in each industry/market on market size reveals a downward-sloping linear relationship.

As in the extant literature (e.g. Sutton 1991, Robinson and Chiang 1996 and Ellickson 2004a), we test the concentration prediction by estimating a lower bound function. Assume $C_{1}$ is drawn from a Weibull distribution. This assumption reflects the fact that $C_{1}$ is an extreme value of the distribution of brand shares and is necessarily bounded below at zero. Since $C_{1}$ is also constrained to lie between zero and one, we take a logit transformation: $\widetilde{C}_{1 m} \equiv \log \left(\frac{C_{1 m}}{1-C_{1 m}}\right)$. Assume also that concentration in market $m$ is distributed as follows: $\widetilde{C}_{1 m}=B$ (market size $\left.m\right)+\omega_{m}$, where $B$ (market size $\left._{m}\right)$ is a parametric function of observed market size that characterizes the lower bound. The random variable $\omega_{m}$ is a random draw from a Weibull distribution with shape parameter $\alpha$ and scale parameter $\beta$. Since we expect concentration to be inversely-related to market size in smaller markets, we follow the literature and specify $B$ (market size $m$ ) as a quadratic polynomial of the inverse of market size:

$$
\widetilde{C}_{1 m}=a+\frac{b}{\text { market } \operatorname{size}_{m}}+\frac{c}{\left(\text { market } \operatorname{size}_{m}\right)^{2}}+\omega_{m}
$$

This parametric formulation also provides us with a characterization of the limiting concentration as the market size approaches infinite: $a=\log \left(\frac{C_{1 \infty}}{1-C_{1 \infty}}\right)$ when market size approaches infinite.

The parameters for the bound function, $(a, b, c)^{\prime}$, and the Weibull distribution, $(\alpha, \beta)^{\prime}$, are estimated using the two-step procedure from Smith (1994). ${ }^{22}$ Standard errors are computed

\footnotetext{
${ }^{21}$ Sutton (1991) also finds similar evidence of a non-monotonic relationship between concentration and market size for advertising-intensive industries. This non-monotonicity is consistent with the theory.

${ }^{22}$ In the first stage, we estimate $(a, b, c)^{\prime}$ from (2) using a simplex search subject to the constraint $\widetilde{C}_{1 m}-a-$
} 

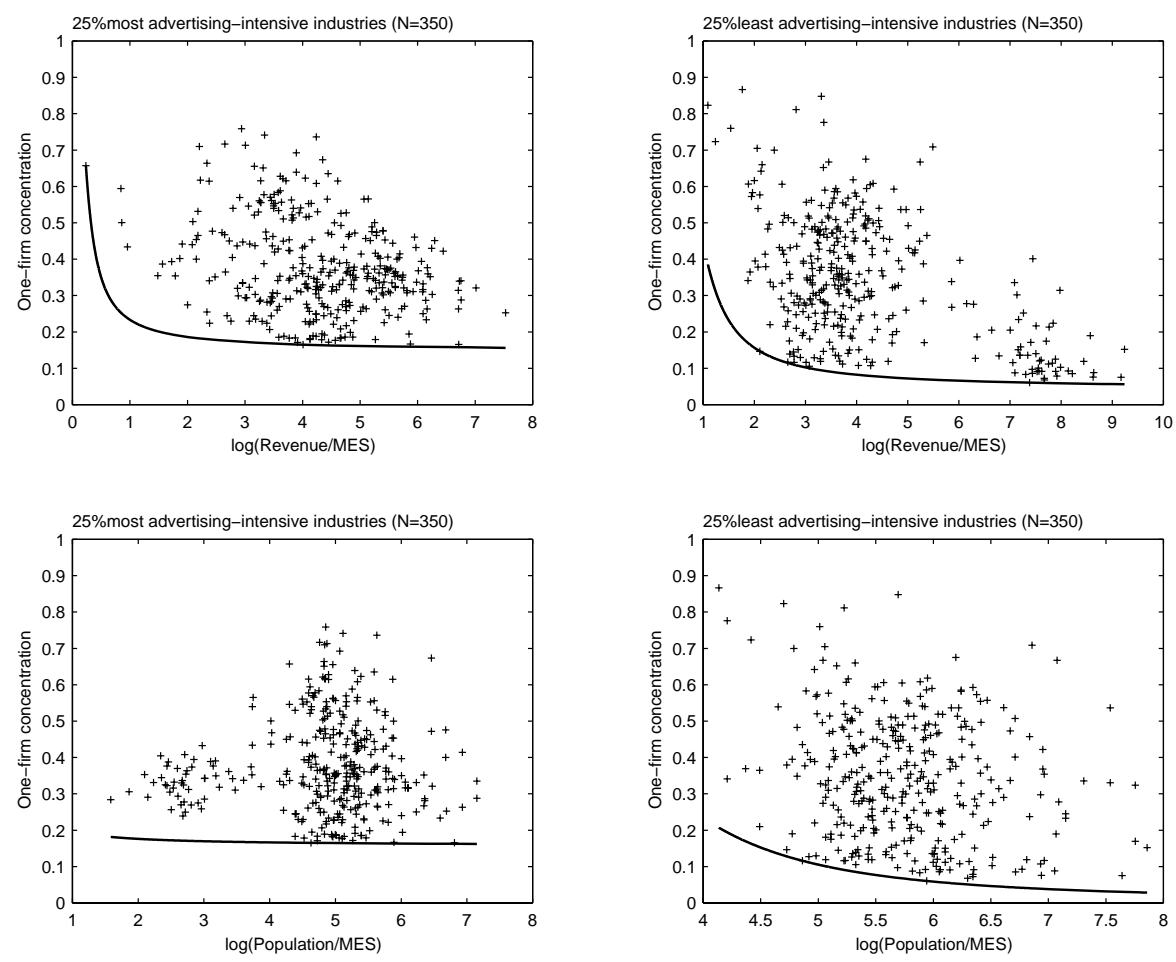

Figure 2: Concentration vs. Market Size (and estimated lower bounds) for advertising-intensive versus non-advertising-intensive industries

using the simulation method discussed in Smith (1994).

Estimation results are reported in Table 4. In general, we observe a steeper bound function for non-advertising intensive industries, driven mainly by the linear as opposed to the quadratic term. To illustrate, we plot the estimated bound functions in Figure 2. Furthermore, the estimated limiting bounds reported in Table $4, C_{1 \infty}$, are much lower for non-advertising intensive than for advertising intensive industries (about 15\% and less than 5\% respectively). The estimated limiting bounds are not statistically different from zero at the $95 \%$ confidence level in the case of nonadvertising intensive industries. These results are all consistent with the theory. Our findings suggest that concentration is bounded away from zero in advertising intensive industries, but not in non-advertising intensive industries. Interestingly, the findings of a relationship between concentration and advertising contrasts with an earlier literature in which the correlation between concentration levels and advertising levels in consumer goods industries were found to be small and, often, statistically insignificant (e.g. Telser 1964 and Comanor and Wilson 1974). The contrast to earlier findings is likely due both to the quality of the data used herein as well as the use of an approach guided by game theory.

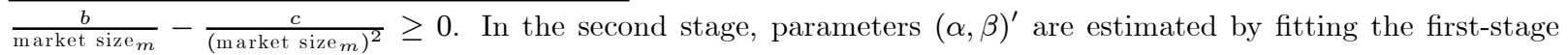
prediction errors to a Weibull distribution. 


\begin{tabular}{|r|cc|cc|cc|cc|}
\hline & \multicolumn{3}{|c|}{$\begin{array}{c}\text { Concentration versus } \\
\text { revenues/MES }\end{array}$} & \multicolumn{3}{c|}{$\begin{array}{c}\text { Concentration versus } \\
\text { population/MES }\end{array}$} \\
\cline { 2 - 9 } & \multicolumn{2}{|c|}{ Ad-Intensive } & \multicolumn{2}{|c|}{ Non-Ad-Intensive } & \multicolumn{2}{|c|}{ Ad-Intensive } & \multicolumn{2}{c|}{ Non-Ad-Intensive } \\
& coefficient & s.e. & coefficient & s.e. & coefficient & s.e. & coefficient & s.e. \\
$b$ & -1.764 & 0.112 & -3.136 & 0.217 & -1.679 & 0.155 & -5.983 & 1.559 \\
$c$ & 0.577 & 0.373 & 2.888 & 1.032 & 0.274 & 0.672 & 19.367 & 10.067 \\
$c$ & -0.003 & 0.053 & 0.029 & 1.204 & 0.000 & 0.034 & -0.753 & 11.841 \\
$\alpha$ & 1.225 & 0.035 & 1.812 & 0.051 & 1.237 & 0.035 & 2.114 & 0.054 \\
$\beta$ & 2.050 & 0.080 & 2.211 & 0.083 & 2.015 & 0.080 & 2.395 & 0.098 \\
$C_{1 \infty}$ & 0.146 & 0.041 & 0.042 & 0.022 & 0.157 & 0.054 & 0.003 & 0.011 \\
$\log$-likelihood & \multicolumn{2}{|c|}{275.555} & \multicolumn{2}{|c|}{397.032} & 282.326 & \multicolumn{3}{c|}{428.447} \\
\hline
\end{tabular}

Table 4: Estimated Lower Bound Functions for concentration in advertising-intensive and nonadvertising-intensive industries.

\section{E Summary}

Collectively, the results from the last three sub-sections indicate that advertising intensive industries appear to remain concentrated irrespective of market size. Corresponding to this result, advertising levels escalate in larger markets, but the number of advertised brands does not. ${ }^{23}$ These results are consistent with the basic ESC model whereby advertising generates economies of scale even in very large markets. In this respect, our findings are consistent with a model in which advertising is borne mainly as a fixed and sunk cost, as opposed to a variable cost. Furthermore, the results are consistent with a model in which branding increases consumer willingness-to-pay in a manner similar to a model of vertical product differentiation, as opposed to a model of horizontal differentiation.

\section{Share Asymmetries and Sequential Entry}

The results of the previous subsection are suggestive of a role for advertising as a barrier to entry. This barrier limits the number of brands in a market and enables at least one brand to garner a non-trivial market share. In this subsection, we examine the identity of this leading brand. Of interest is whether early entry in a market can lead to a strategic advantage whereby the first entrant can secure a share-leadership position. In the absence of the ESC result, sequential entry would still lead to fragmentation in large markets and, hence, an early-entry effect would be dissipated. Unfortunately, historic entry data are not readily available for all 31 industries and need to be collected manually. The following analysis focuses on two industries, coffee and mayonnaise, for which entry data could be collected from various sources. Focusing on two

\footnotetext{
${ }^{23}$ Although not reported, we also examined the lower bound in concentration separately for advertised brands and non-advertised brands. We estimate a limiting concentration level of about 0.15 for advertised brands and 0.0082 for non-advertised brands. These findings are also consistent with the theory insofar as the subsegment of non-advertised brands fragments in larger markets. Results are available from the authors upon request.
} 
industries limits the generalizeability of the results. However, we will demonstrate that brand shares in all of our industries exhibit a considerable amount of spatial dependence across markets. Since the order of entry accounts for most of the spatial dependence in the market shares of coffee and mayonnaise brands, the analysis in this section can be seen as a preliminary attempt to explain a general phenomenon.

\section{A Geographic Patterns in "Leading Brand" Shares}

Across the 31 industries, we observe a fair amount of dispersion in a brand's shares across markets. Using the within-market mean share for the top two brands per industry, we see an average dispersion of 0.73 (its standard deviation divided by its mean). In general, this dispersion in brand shares leads to considerable variation in the rank-orders of shares across markets. Across industries, we see an average of 8 different brands that are a local share-leader in at least one market, with a range of 1 to 27 (i.e. one industry has 27 different brands that are a local leader in at least one of the markets). In fact, on average across industries, a local leader dominates a maximum of $64 \%$ of the markets. In only three industries do we observe a single consistent share-leader across all markets: Cereals, Cream Cheese and Frozen Toppings.

We focus on the coffee and mayonnaise industries to illustrate these patterns in more detail. Figure 3 maps the geographic distribution of within-market mean shares for the top two ground coffee and mayonnaise brands across the 50 US markets. Each circle's radius is proportional to the size of the share in a given market. The maps indicate that brand shares vary considerably across markets. The average market share of Folgers ranges from 0.15 in Pittsburgh to 0.57 in Kansas City. For Maxwell House, average local market shares are between 0.04 (Seattle) and 0.45 (Cleveland). The maps also indicate that, within an industry, the rank-order of shares varies considerably across geographic areas. Maxwell House shares are strongest in the northeast, precisely where Folgers is weakest. In general, Folgers clearly dominates the ground coffee industry in the west and north central markets. But, Maxwell House dominates the East Coast.

The lower half of Figure 3 illustrates similar patterns for the two leading mayonnaise brands, Kraft and Unilever. Geographically, shares are even more dispersed than in the coffee data. Local shares for Kraft are between 0.14 in New York and 0.77 in Kansas City. For Unilever, local shares are between 0.09 and 0.73. Spatial patterns also appear in the data insofar as Unilever shares dominate markets in the North East and West Coast, whereas Kraft shares dominate in the central and midwestern markets.

In both the coffee and mayonnaise industries, we observe four different local leading brands. For coffee, none of the four brands dominates in more than $52 \%$ of the markets. In mayonnaise, none of the four brands dominates in more than $72 \%$ of the markets. Interestingly, while the 

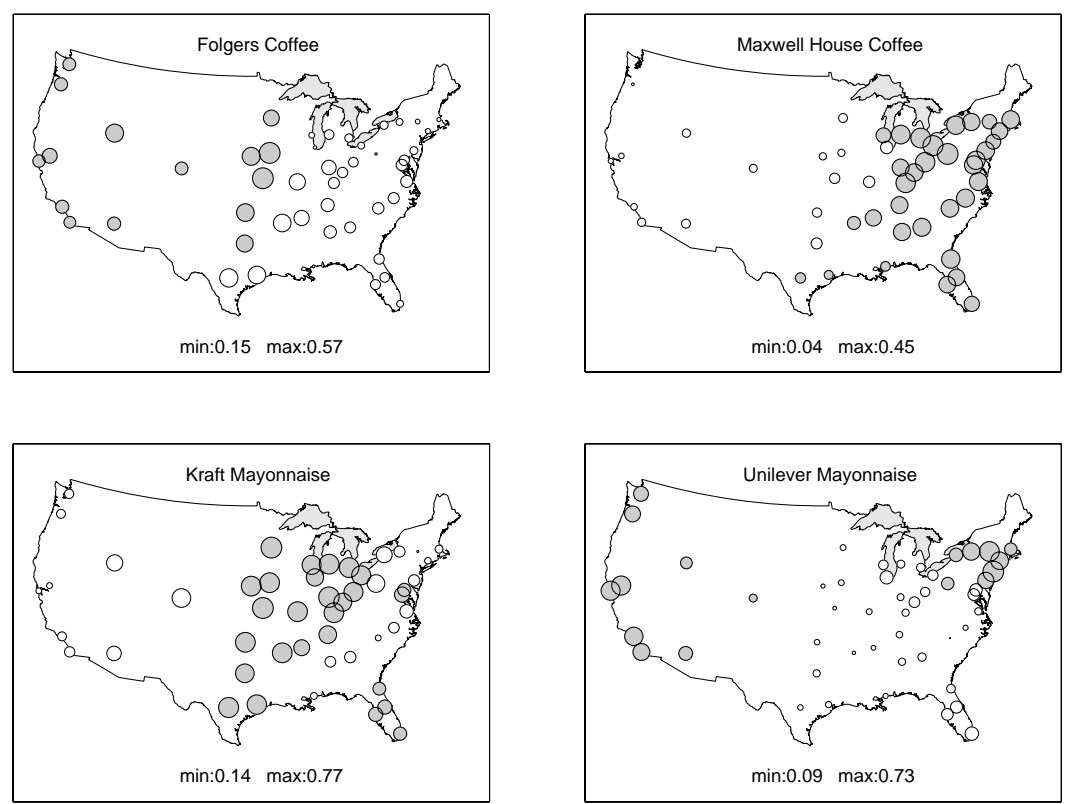

Figure 3: The joint geographic distribution of share levels and early entry across US markets. Circles are proportional to share levels. Shaded circles indicate a brand locally moved first.

largest brands tend to have entered all 50 markets, the average brand in our database has entered only 11.4 markets, on average. Clearly, the local market structure is considerably different from the national market structure for most of these industries.

These geographic patterns are also very persistent over time. Although not reported, DickeyFuller tests systematically reject unit roots for almost all the share series using the top two brands in each industry and market. Furthermore, although not reported, an analysis of variance using the top two brands in each of the 31 industries across markets and time systematically reveals that geographic variance is considerably larger than time-series variation. ${ }^{24}$ Hence, the geographic patterns we observe roughly correspond to "long-run" patterns in market structures. To illustrate, for the top two brands in each of the ground coffee and mayonnaise data, we plot each brand's time series for three distinct markets, Kansas City, San Francisco and Pittsburgh, each from a different region of the US. The plots reveal that the variation in a brand's share across these three markets is considerably larger than the variation across time within each market. In addition, the data appear relatively stationary over time. ${ }^{25}$

\footnotetext{
${ }^{24}$ We ran 62 separate sets of regressions of market shares on time and market fixed-effects for each of the top two national brands in each industry. The $R^{2}$ for market effects was over $80 \%$ on average across brand and was larger than $50 \%$ for all the brands. These regression results and the Dickey-Fuller test results are all available from the authors upon request.

${ }^{25}$ A similar observation regarding share stationarity over time has been suggested by Dekimpe and Hanssens (1995).
} 

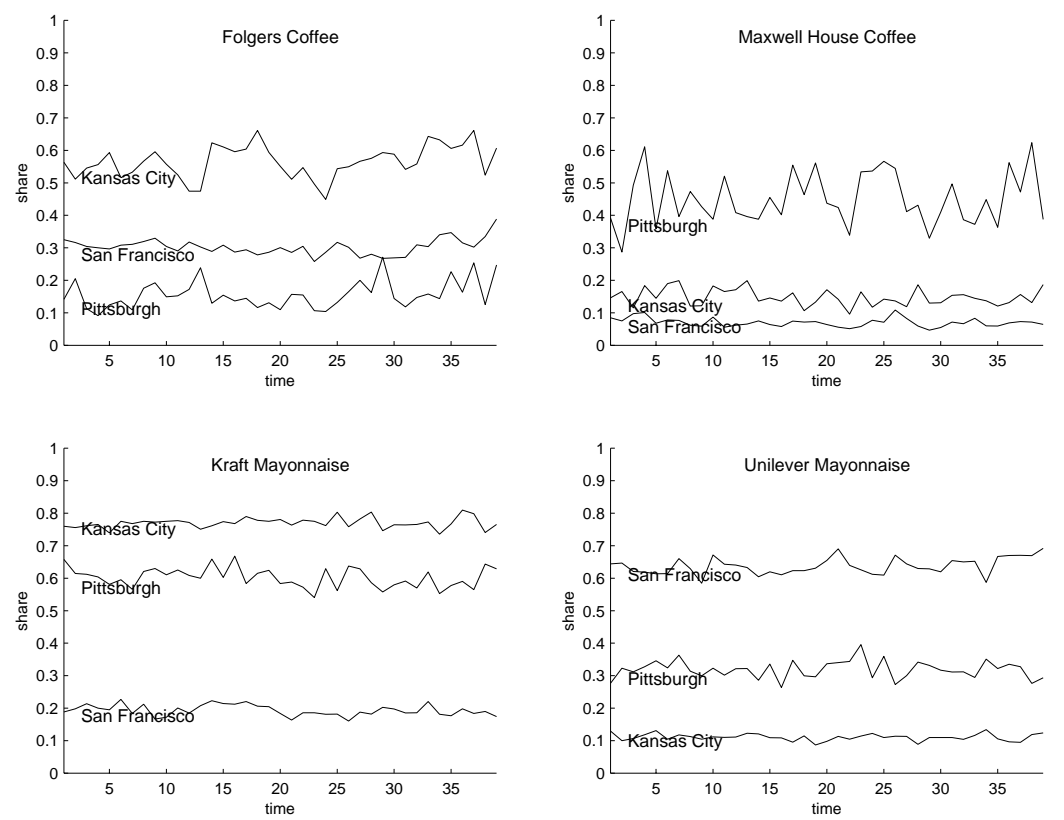

Figure 4: Local time-series variation in shares by brand and several local markets.

\section{B Historic Entry}

We now test whether early entry status is a good predictor for a brand's market share. Figure 3 maps the joint geographic distribution of entry and market share. Shaded circles indicate those markets in which a brand had at least a 5 year entry advantage. For example, Folgers started in the west and moved east whereas Maxwell House started in the east and moved west. The maps reveal a strong positive correlation between a brand's share level and its early entry status.

This relationship is now tested more formally. Unlike Mazzeo and Cohen (2003), historic entry is treated as exogenous. ${ }^{26}$ In the coffee category, we include a third brand, Hills Brothers, to ensure that we always have the top two brands in each market. The dependent variable is the within-market mean share for each brand: $\overline{y_{i m}}=\frac{1}{T} \sum_{t} y_{i m t}$ for brand $i$, market $m$ and time period $t$. Our regressors consist of brand dummies and "FirstEntry," an indicator for whether a brand was the first entrant in a market:

$$
\text { FirstEntry }_{i m}=\left\{\begin{array}{ll}
1, & \text { if brand } i \text { entered market } m \text { first } \\
0, & \text { else }
\end{array} .\right.
$$

Table 5 reports four sets of regression results, by industry. In the first column, we include only entry; in the second we include only brand dummies; in the third we include both brand and entry.

\footnotetext{
${ }^{26}$ Since the brands we study originated during the mid to late $19^{\text {th }}$ century, it is unlikely that technology at the time would have been adequate to coordinate a national roll-out. Furthermore, Folgers and Maxwell House diffused over a period of nearly one century. Similarly, it is unlikely that a firm selected an "optimal" target market to initialize the diffusion of its brand across the US.
} 


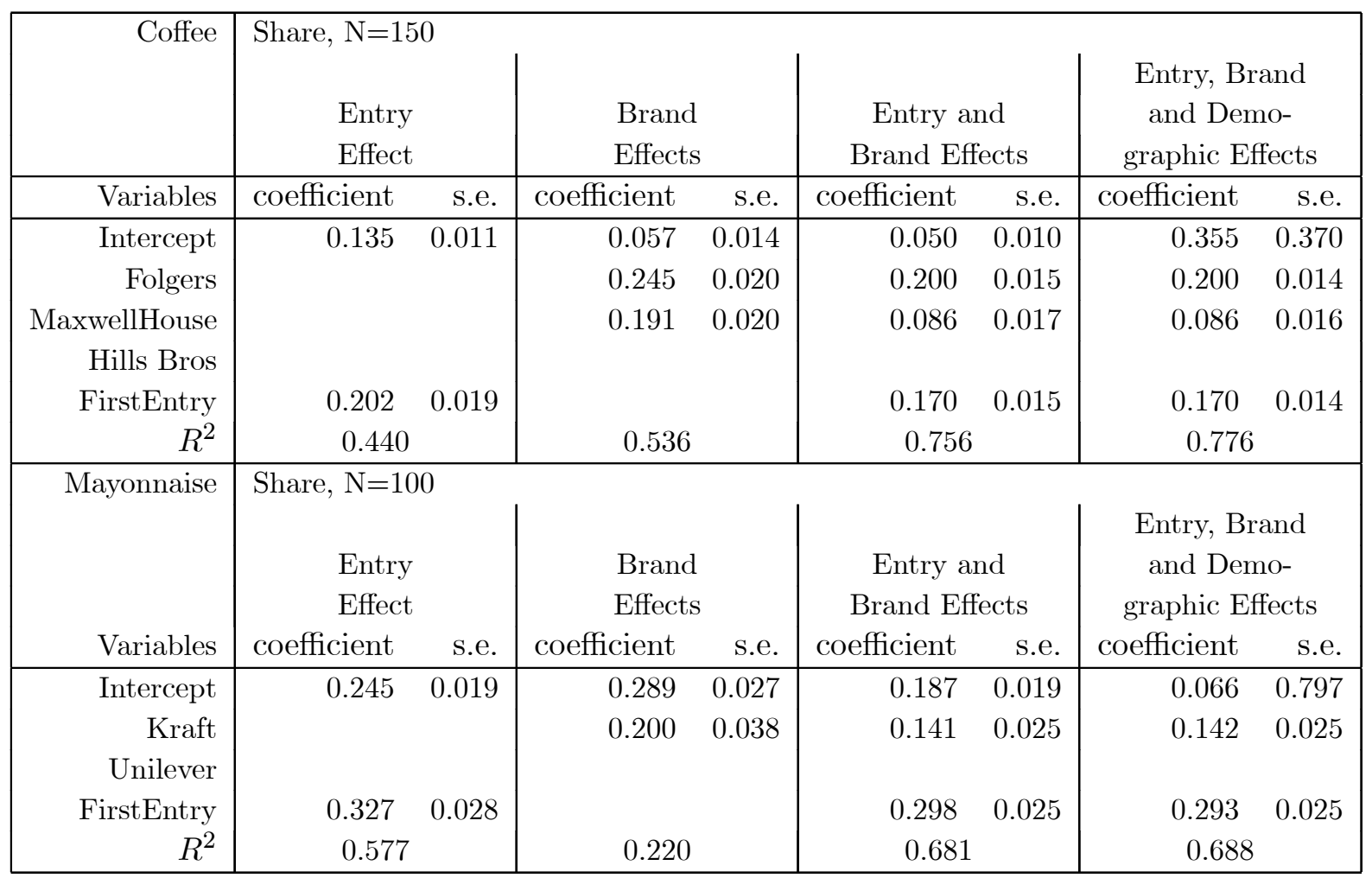

Table 5: Impact of entry on share levels

In the fourth column, we include market demographic variables to control for local differences in demand: HomeValue>150K, Elderly, Education, Ethnic, Income>50K, AverageIncome, Hispanic, Hsize, Age. The demographic coefficients are suppressed to save space since they had very small effects. In both industries, historic entry alone explains a non-trivial portion of the total crosssectional variation in current shares, $44 \%$ in coffee and $58 \%$ in mayonnaise. Conditioning on both entry and brand accounts for $76 \%$ of the variation in coffee and $68 \%$ in mayonnaise. In coffee, early entry status appears to generate roughly a $17 \%$ benefit to share level. In mayonnaise, early entry generates a $29 \%$ share benefit. The entry effects are fairly robust both to the inclusion of brand effects and the inclusion of demographic variables. However, the brand effects are sensitive to the inclusion of entry as, in both industries, the brand effects fall once entry is accounted for. Finally, the magnitudes of the entry effects are such that the rank-order of shares for the top brands will be influenced by the order of entry.

To check the robustness of the entry effect, we now investigate the impact of entry on perceived quality levels for these brands. We re-run the regressions from Table 5 using the perceived quality index of each brand in each market as the dependent variable. Unlike market share, which is an outcome of the ESC investment, the perceived brand quality is a more direct measure of the ESC investment itself. The Y\&R measures of perceived brand quality for each brand and market serve as the dependent variable. Results appear in Table 6. As before, entry explains 


\begin{tabular}{|c|c|c|c|c|c|c|c|c|}
\hline Coffee & \multicolumn{8}{|c|}{ Perceived Quality, $N=150$} \\
\hline \multirow[t]{2}{*}{ Variables } & \multicolumn{2}{|c|}{$\begin{array}{l}\text { Entry } \\
\text { Effect }\end{array}$} & \multicolumn{2}{|c|}{$\begin{array}{l}\text { Brand } \\
\text { Effects }\end{array}$} & \multicolumn{2}{|c|}{$\begin{array}{c}\text { Entry and } \\
\text { Brand Effects }\end{array}$} & \multicolumn{2}{|c|}{$\begin{array}{l}\text { Entry, Brand, } \\
\text { and Demo- } \\
\text { graphic Effects }\end{array}$} \\
\hline & coefficient & s.e. & coefficient & s.e. & coefficient & s.e. & coefficient & s.e. \\
\hline Intercept & 0.100 & 0.002 & 0.080 & 0.002 & 0.079 & 0.002 & 0.084 & 0.072 \\
\hline Folgers & & & 0.053 & 0.003 & 0.048 & 0.003 & 0.048 & 0.003 \\
\hline Maxwell House & & & 0.034 & 0.003 & 0.022 & 0.003 & 0.022 & 0.003 \\
\hline Hills Bros & & & & & & & & \\
\hline FirstEntry & 0.027 & 0.004 & & & 0.019 & 0.003 & 0.019 & 0.003 \\
\hline$R^{2}$ & \multicolumn{2}{|l|}{0.221} & \multicolumn{2}{|c|}{0.652} & \multicolumn{2}{|c|}{0.726} & \multicolumn{2}{|c|}{0.758} \\
\hline Mayonnaise & \multicolumn{8}{|c|}{ Perceived Quality, $N=100$} \\
\hline \multirow[t]{2}{*}{ Variables } & \multicolumn{2}{|c|}{$\begin{array}{l}\text { Entry } \\
\text { Effect }\end{array}$} & \multicolumn{2}{|c|}{$\begin{array}{l}\text { Brand } \\
\text { Effects }\end{array}$} & \multicolumn{2}{|c|}{$\begin{array}{c}\text { Entry and } \\
\text { Brand Effects }\end{array}$} & \multicolumn{2}{|c|}{$\begin{array}{l}\text { Entry, Brand, } \\
\text { and Demo- } \\
\text { graphic Effects }\end{array}$} \\
\hline & coefficient & s.e. & coefficient & s.e. & coefficient & s.e. & coefficient & s.e. \\
\hline Intercept & 0.487 & 0.002 & 0.484 & 0.002 & 0.476 & 0.002 & 0.504 & 0.069 \\
\hline Kraft & & & 0.032 & 0.003 & 0.028 & 0.002 & 0.027 & 0.002 \\
\hline Unilever & & & & & & & & \\
\hline FirstEntry & 0.029 & 0.004 & & & 0.023 & 0.002 & 0.024 & 0.002 \\
\hline$R^{2}$ & 0.412 & & 0.518 & & 0.77 & & 0.78 & \\
\hline
\end{tabular}

Table 6: Impact of Entry on Perceived Quality Levels

a substantial portion of the total variation in perceived brand quality across markets in both coffee and mayonnaise (22\% for coffee and $41 \%$ for mayonnaise). The scale of these measures is really ordinal in nature, so we do not attribute much importance to the levels of our parameter estimates. Nevertheless, as before, conditioning on entry does slightly lower the expected quality differentials across brands within a market.

Finally, we show that entry has a similar predictive ability for a brand's advertising intensity (in GRPs) across markets. Since we are mainly interested in relative advertising across brands rather than absolute advertising levels, we measure advertising as: $S O V_{i m}=\frac{\Sigma_{t} G R P_{i m t}}{\Sigma_{j} \Sigma_{t} G R P_{j m t}}$. Marketing practitioners typically refer to this measure as a brand's advertising "share of voice." The entry effect is interacted with the brand to control for the fact that GRPs do not capture market-specific differences in the effectiveness of firms' advertising creative and advertising content. Results are reported in Table 7. For most of the brands, we observe a positive impact of entry on advertising intensity. An exception is Folgers, which has a significantly negative coefficient. Folgers appears to advertise more aggressively in markets where the coffee category is relatively large, as opposed to where its own share is large. 


\begin{tabular}{|c|c|c|c|c|c|}
\hline \multirow[b]{2}{*}{ Variables } & \multicolumn{2}{|c|}{$\begin{array}{c}\text { Coffee, } N=69 \\
\text { Entry and } \\
\text { Brand Effects }\end{array}$} & \multirow[b]{2}{*}{ Variables } & \multicolumn{2}{|c|}{$\begin{array}{c}\text { Mayonnaise, } N=46 \\
\text { Entry and } \\
\text { Brand Effects }\end{array}$} \\
\hline & Coefficient & s.e. & & Coefficient & s.e. \\
\hline Intercept & 0.024 & 0.006 & Intercept & 0.400 & 0.014 \\
\hline Folgers & 0.329 & 0.009 & Kraft & 0.104 & 0.021 \\
\hline $\begin{array}{c}\text { Maxwell House } \\
\text { Hills Bros }\end{array}$ & 0.255 & 0.010 & Unilever & & \\
\hline FirstEntry Folgers & -0.024 & 0.011 & Entry Kraft & 0.073 & 0.022 \\
\hline FirstEntry MH & 0.022 & 0.011 & Entry Unilever & 0.074 & 0.022 \\
\hline FirstEntry HB & 0.011 & 0.019 & & & \\
\hline$\overline{R^{2}}$ & 0.965 & & $\overline{R^{2}}$ & & \\
\hline
\end{tabular}

Table 7: Impact of entry on advertising levels

\section{Spatial Dependence in Brand Shares}

The entry results of the previous subsection are limited to two industries. We will now show that brand shares in all 31 industries exhibit spatial dependence. We then show that entry captures most of the spatial dependence in brand shares in the coffee and mayonnaise industries. Hence, our entry findings may be associated with a more general pattern we observe across industries.

Referring again back to Figure 3, the maps also illustrate that a brand's shares are spatially dependent, i.e., a given brand's shares co-vary positively across nearby markets. To quantify this dependence, we use the non-parametric approach of Conley and Topa (2002) to estimate the spatial autocorrelation in brand shares as a function of the distance between a pair of markets. Suppose the observed share data, $y_{m}$, are indexed by locations $m$ with coordinates $\omega_{m}$ in a Euclidean space. We assume the dependence between the observations is a function of the physical distance between their locations. Thus, two random variables, $y_{m}$ and $y_{m^{\prime}}$, become increasingly dependent as the distance between $m$ and $m^{\prime}$ shrinks (i.e. as they become "close") ${ }^{27}$ We define the spatial autocovariance function as:

$$
\operatorname{cov}\left(y_{m}, y_{m^{\prime}}\right)=f\left(D_{m m^{\prime}}\right)
$$

where $D_{m m^{\prime}}=\left\|\omega_{m}-\omega_{m^{\prime}}\right\|$ is the Euclidean distance between locations $m$ and $m^{\prime}$. The spatial autocovariance function, 3, can be estimated non-parametrically using kernel-smoothing over a grid of distances. At a given gridpoint $\delta$, the estimated spatial autocovariance is:

$$
\widehat{f}_{y}(\delta)=\sum_{m, m^{\prime} \neq m} W_{N}\left\|\delta-D_{m m^{\prime}}\right\|\left(y_{m}-\bar{y}\right)\left(y_{m^{\prime}}-\bar{y}\right)
$$

\footnotetext{
${ }^{27}$ Formally, we assume our data, $y_{m}$, are second order stationary and isotropic (i.e. dependent on distance between two locations and not on direction). See Conley (1999) for a more detailed discussion of the regularity conditions of this model.
} 
where $W_{N}\left\|\delta-D_{m m^{\prime}}\right\|$ are weights. ${ }^{28}$ To obtain the corresponding spatial autocorrelation function $(\mathrm{ACF})$, we standardize 6 by the sample variance of $y$ :

$$
\widehat{\rho}_{y}(\delta)=\frac{\widehat{f}_{y}(\delta)}{\operatorname{var}(y)}
$$

Note that the summation in 4 does not include pairs of observations from the same market (i.e. where $D_{m m}=0$ ). Decomposing observed shares into two orthogonal components, an i.i.d. component and a dependent component, then our estimate of the covariance, $\widehat{f_{y}}$, captures only the latter. Then, by construction, the estimated ACF at zero, $\widehat{\rho}_{y}(0)$, captures the fraction of total variance in $y$ that is accounted for by the dependent component. ${ }^{29}$

We test the statistical significance of our ACF point estimates using the bootstrap procedure of Conley and Topa (2002). The data are re-sampled with replacement from their empirical marginal distributions to create pseudo-samples that are spatially independent. An acceptance region for the null hypothesis of spatial independence is constructed using quantiles of the pseudo-sample estimates of $\widehat{\rho}\left(y_{m}, y_{m}^{\prime}\right)$.

The empirical distribution of inter-market distances in the data is reported in Figure 5. Figure 6 plots the spatial ACFs for the within-market mean shares in the ground coffee and mayonnaise industries for a range of 1000 miles. The spatial ACF is indicated by the circles. Specifically, the $\mathrm{ACF}$ is estimated for $\overline{y_{i m}}=\frac{1}{T} \sum_{t} y_{i m t}$, where $y_{i m t}$ is the market share of brand $i$ in market $m$ during month $t$. The $95 \%$ acceptance region for the null hypothesis of spatial independence is also reported. The spatial ACFs are strikingly similar across each of the brands. In each case, the spatial autocorrelation is positive and significant over a distance of 500-600 miles. A high share in one market coincides with a high share in geographically close markets. Since this dependence

\footnotetext{
${ }^{28}$ For instance, we use the uniform kernel with bandwidth $\eta=200$ miles
}

$$
W_{N}\left\|\delta-D_{m m^{\prime}}\right\|= \begin{cases}\frac{1}{N_{\delta}} & \text { if }\left\|\delta-D_{m m^{\prime}}\right\|<\eta \\ 0 & \text { else }\end{cases}
$$

where $N_{\delta}$ is the number of location pairs within $\delta \pm \eta$ distance. Defining the distance class $\mathcal{D}_{\delta \eta}$ as the combinations of $\left(m, m^{\prime}\right), m>m^{\prime}$ (because of symmetry), for which $\left\|\delta-D_{m m^{\prime}}\right\|<\eta$, the empirical estimator for the covariance function used in this paper reduces to (Cressie 1993):

$$
\widehat{f}_{y}(\delta)=\sum_{\forall\left(m, m^{\prime}\right) \in \mathcal{D}_{\delta \eta}} \frac{\left(y_{m}-\bar{y}\right)\left(y_{m^{\prime}}-\bar{y}\right)}{N_{\delta}} .
$$

Experimentation with other kernels (e.g. Gaussian and Bartlett) had little impact on our estimates of the spatial $\mathrm{ACF}$.

${ }^{29}$ More formally, suppose that shares can be decomposed into an indiosyncratic as well as a dependent component:

$$
y_{m}=\varepsilon_{m}+\nu_{m}
$$

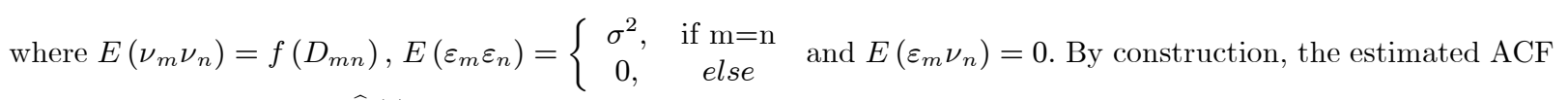
at zero is just $\widehat{\rho}_{y}(y)=\frac{\widehat{f}_{y}(0)}{f_{y}(0)+\sigma^{2}}$ where the denominator is simply the total geographic sample variance in shares. 


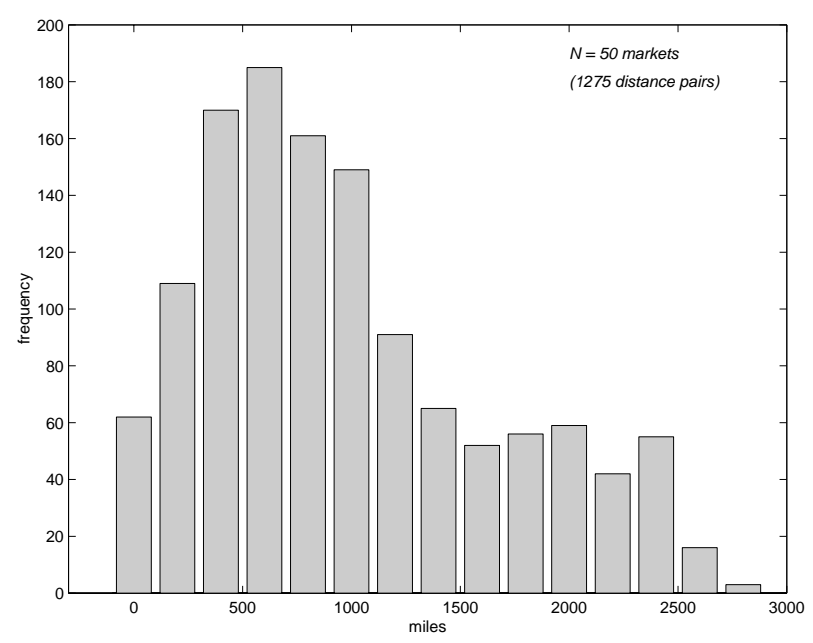

Figure 5: Distribution of inter-market distances in miles.

arises from the within-market mean shares, we roughly interpret this pattern as a persistent "long-run" phenomenon. ${ }^{30}$ Finally, the estimate of ACF at zero, $\widehat{\rho}(0)$, roughly corresponds to the proportion of total cross-market variance in share associated with the spatially-dependent error component. Since $\widehat{\rho}(0)$ exceeds 0.5 , we conclude that the co-variation in shares across markets account for a substantial portion of the total cross-market variation in shares.

The results above generalize across all 31 industries. Table C.IV, in the Appendix, reports the spatial dependence findings for the within-market mean shares of the top two brands in each of the 31 industries. The table reports the estimated spatial correlation at zero distance, $\widehat{\rho}(0)$, and the average spatial correlation over the set of grid points between zero and 600 miles. A summary of these findings appears in Table 8. On average, the spatially-dependent component of market shares accounts for over half the total variance. We conclude that understanding the sources of the spatial covariance are also important for understanding the geographic distribution of shares. Similarly, we find that the spatial correlation is, on average, about 0.2 for cities up to 600 miles apart. Given the distribution of distances reported in Table 5, this finding suggests that the dependence persists for a large proportion of our geographic markets.

Having established the presence of spatial dependence across our industries, we now test for a connection between this dependence and the geographic distribution of entry in the coffee and mayonnaise industries. Using the regression results in column four from Table 5, we compute the estimated residuals, the component of shares not explained by brand, entry or observed market

\footnotetext{
${ }^{30}$ Although not reported, estimates of the spatial ACF based on the monthly deviations from the within-market mean share do not reveal any evidence of spatial dependence. We also computed a multi-dimensional ACF that used both time and space as predictors for covariance levels. This generated a covariance surface that was found to be flat near the origin over time dimension. These results are available from the authors upon request.
} 

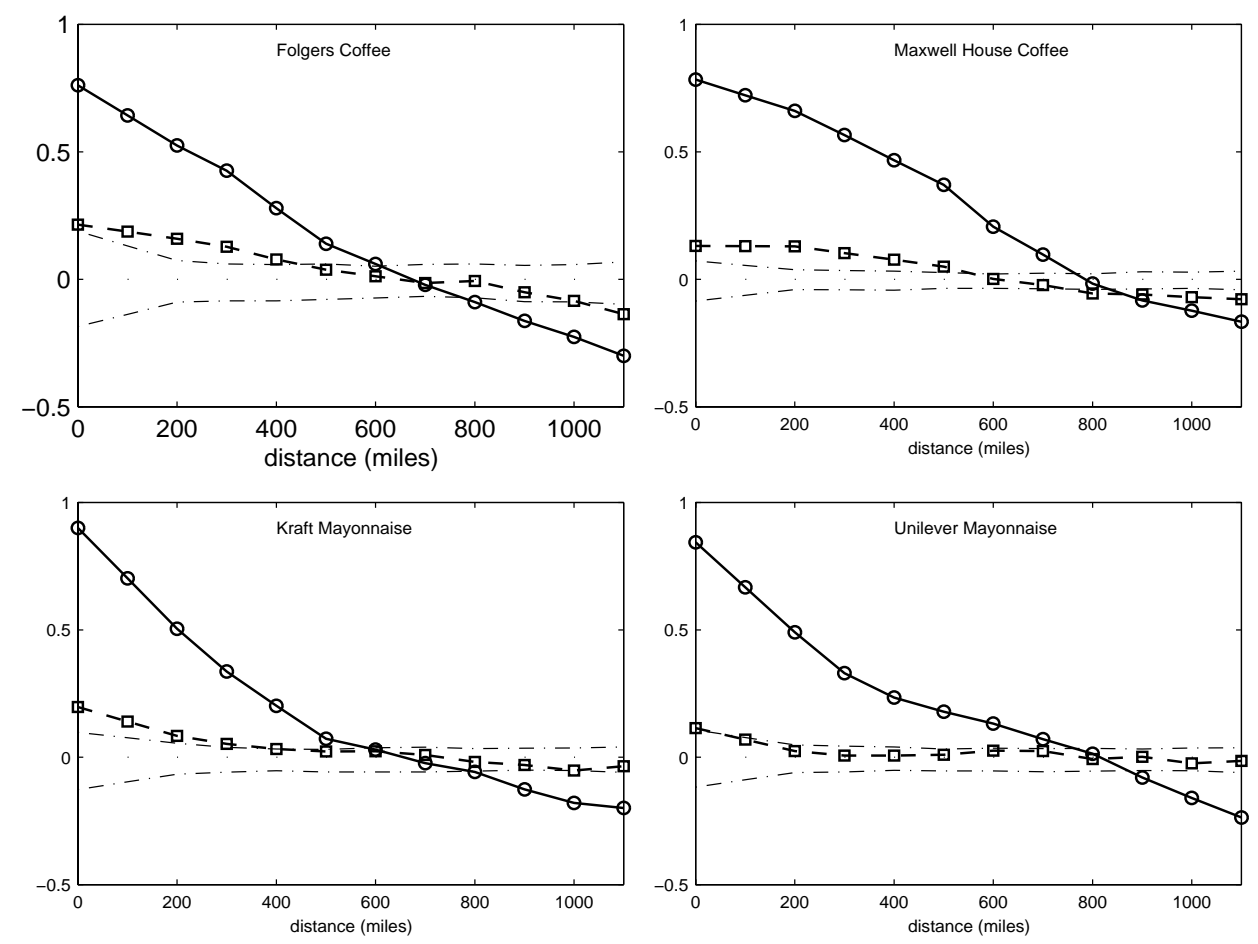

$\bigcirc$ SpatCov(share)/Nar(share)

$\square-\square$ SpatCov(residuals)/Nar(share)

- - Bootstrapped independence region

Figure 6: Accounting for spatial covariation using the first entry status.

\begin{tabular}{|r|cc|cc|}
\hline & \multicolumn{2}{|c|}{ Correlation at zero distance } & \multicolumn{2}{c|}{ Correlation between zero and 600 miles } \\
& top brand & second brand & top brand & second brand \\
\hline mean & 0.59 & 0.61 & 0.20 & 0.20 \\
median & 0.58 & 0.53 & 0.20 & 0.23 \\
standard deviation & 0.20 & 0.25 & 0.12 & 0.15 \\
$\min$ & 0.22 & 0.28 & 0.01 & -0.04 \\
$\max$ & 1.01 & 1.32 & 0.46 & 0.50 \\
\hline
\end{tabular}

Table 8: Summary of Estimated Spatial Correlation Across Industries 
demographics:

$$
\widehat{\varepsilon}_{i m}=\overline{y_{i m}}-\widehat{D u m m}_{i}-\text { FirstEntry }_{i} \widehat{\beta}^{\text {Entry }}-\text { Demographics }_{m} \widehat{\beta}^{\text {Demog }} .
$$

A spatial autocorrelation function can then be computed for these estimated residuals: $\widehat{\rho}_{\varepsilon_{i}}\left(\right.$ Dist $\left.t_{m n}\right)=$ $\frac{E\left(\widehat{\varepsilon}_{i m}, \widehat{\varepsilon}_{i m} \mid D_{i s t_{m n}}\right)}{\operatorname{var}\left(\widehat{\varepsilon}_{i}\right)}$. As before, of particular interest is the predicted spatial auto-correlation at zero which indicates the proportion of variance in the residuals accounted for by a spatially-dependent component. Referring back to Figure 6, we plot the ACF of the residuals as indicated by the squares. The results indicate that, after conditioning on entry, the dependent component of shares becomes very small relative to the total variance. In both industries, the share of variance accounted for by the dependent component falls by over $50 \%$. We conclude that entry accounts for a sizeable proportion of the spatial dependence observed in the data.

In summary, the theory predicts that order-of-entry will influence the rank-order of market shares in advertising intensive industries. For two of our industries, we find that entry is a very good predictor for a brand's share levels and advertising share-of-voice, accounting for a large proportion of the total geographic variance in shares. Entry also influences the rank-order of shares, even after controlling for brand-specific effects. Finally, entry accounts for a large proportion of the geographic covariance in a brand's shares across markets. After conditioning on entry, the proportion of total share variance accounted for by the dependent component across markets falls over $50 \%$. Thus, the historic geographic diffusion of brands across geographic markets appears to be a good predictor for the observed spatial dependence in current market shares. Collectively, these results are consistent with a theory where early entrants advertise more aggressively and, in turn, garner a higher market share in equilibrium. In the next section, we test the entry theory against several alternative explanations for these geographic asymmetries in brand shares.

\section{Alternative Explanations}

In the previous section, we established an empirical connection between the asymmetric share patterns, for coffee and mayonnaise, and historic entry patterns. In this section, we test several potential alternative sources of firm heterogeneity that could also explain these patterns. First, we consider geographic cost advantages based on a brand's proximity to its production plant (Greenhut, Greenhut and Li 1980). Second, we test for relationships with specific multi-market retailers. For example, manufacturers frequently pay slotting allowances to retailers to obtain premium shelf space for their products (Federal Trade Commission 2001, Israilevich 2004, Sudhir et al. 2004). Third, we look for parent company effects whereby a large food company might possess regional advantages that are passed-on to each of its brands. We also look at the potential role of promotional intensity of firms which, similar to media advertising, might exhibit geographic patterns that are consistent with those of the shares and entry data. 


\section{D.1 Costs and Promotions}

In Table 9, we continue the analysis of share levels across markets for coffee and mayonnaise as we did with entry in table 5. In the first column, we repeat the brand-only effect. In the second column, we add the distance of each brand to its nearest manufacturing plant. The distance effect is insignificant in both industries, suggesting that proximity to production facilities does not engender a strategic advantage in either industry. In the third column, we look at the association between shares and promotions, measured as the fraction of volume sales that is sold on promotion. ${ }^{31}$ In both industries the correlations with promotions are very small and insignificant. Clearly one must be cautious in interpreting these effects due to the potential simultaneity of promotions and shares. In spite of this limitation, it is surprising to observe such little correlation between promotion levels and the cross-section of shares. ${ }^{32}$ In the final column, we pool all the various effects, including entry and demographics. Comparing back to the previous section, we can see that the entry effect is very robust to these other explanations. Overall, we conclude that entry seems to be a considerably better predictor both of expected share levels and of the spatial covariation in a brand's share levels across markets.

\section{D.2 Relationships with Retail Chains}

We now consider the potential role of multi-market retailers in influencing the geographic distribution in brand shares. The practice of slotting-fees could enable a manufacturer to establish a relationships with specific retail chains, which could in turn generate regional advantages in distribution. The conventional wisdom is that slotting fees are paid to the corporate headquarters of a large chain and not to individual store managers (Alexander 2003). We can therefore test this effect by checking whether brand share variation exhibits a retail account component in the retail account level data. A retail account roughly corresponds to the set of stores for a retail chain located in a specific geographic market. We focus on the top two brands at the national level in each of the 31 industries. The dependent variable, $y_{i m a t}$, is the market share of brand $i$ in market $m$, chain $a$ at time $t$. We then decompose the variance in the shares using dummy variables for the markets, $m$, the chains, $a$, and the times, $t$. We focus only on those chains with operations in at least two distinct geographic markets (e.g. Albertsons, Safeway and Krogers) as we cannot separately identify a retailer and a market effect for single-market retailers. A separate

\footnotetext{
${ }^{31}$ Ideally, one would require total promotion expenditures to account correctly for promotion investments.

${ }^{32}$ In contrast, promotions are much more highly correlated with shares within-market over time. In contrast, promotions are more correlated with shares in market-specific the time-series. A separate regression of shares on promotions for each of the top two brands was run for each industry and each of the 50 markets. That is, we ran 100 regressions per industry (2 brands and 50 markets). On average, the $R^{2}$ of a linear regression using price promotions and display promotions to explain market share is 0.38 , whereas the average $R^{2}$ of advertising is 0.06 . As before, we cannot establish a causal relationship from these results. However, it is interesting to observe such a strong correlation between promotions and shares over time within a market versus almost no correlation across markets.
} 


\begin{tabular}{|c|c|c|c|c|c|c|c|c|}
\hline \multirow[t]{2}{*}{ Coffee $N=150$} & \multicolumn{2}{|c|}{ Brand } & \multicolumn{2}{|c|}{ Distance } & \multicolumn{2}{|c|}{ Promo } & \multicolumn{2}{|c|}{ All } \\
\hline & coeff. & s.e. & coeff. & s.e. & coeff. & s.e. & coeff. & s.e. \\
\hline Intercept & 0.057 & 0.014 & 0.062 & 0.019 & 0.107 & 0.034 & 0.625 & 0.381 \\
\hline Folgers & 0.245 & 0.020 & 0.246 & 0.020 & 0.265 & 0.023 & 0.231 & 0.019 \\
\hline Maxwell House & 0.191 & 0.020 & 0.191 & 0.020 & 0.202 & 0.021 & 0.101 & 0.018 \\
\hline Hills Bros & & & & & & & & \\
\hline FirstEntry & & & & & & & 0.170 & 0.014 \\
\hline MinDistToMnfr & & & -0.009 & 0.024 & & & -0.032 & 0.017 \\
\hline $\log ($ Promo $)$ & & & & & 0.063 & 0.039 & 0.075 & 0.036 \\
\hline$R^{2}$ & & & 0.5 & & 0.5 & & 0.7 & \\
\hline Mayonnaise $N=100$ & & & Dist: & nce & Pro & mo & A & \\
\hline & coeff. & s.e. & coeff. & s.e. & coeff. & s.e. & coeff. & s.e. \\
\hline Intercept & 0.289 & 0.027 & 0.306 & 0.040 & 0.312 & 0.112 & 0.161 & 0.750 \\
\hline Kraft & 0.200 & 0.038 & 0.200 & 0.038 & 0.197 & 0.042 & 0.120 & 0.027 \\
\hline Unilever & & & & & & & & \\
\hline FirstEntry & & & & & & & 0.295 & 0.025 \\
\hline MinDistToMnfr & & & -0.024 & 0.039 & & & -0.070 & 0.036 \\
\hline $\log ($ Promo $)$ & & & & & 0.016 & 0.077 & 0.084 & 0.054 \\
\hline$R^{2}$ & & & 0.2 & & 0.2 & & 0.7 & \\
\hline
\end{tabular}

Table 9: Impact of various firm asymmetries on share levels

regression is run for each industry. In general, the $R^{2}$ from retail account fixed-effects are very small compared to market fixed-effects. For instance, in the coffee industry, market fixed-effects and retailer fixed-effects explain $62 \%$ and $14 \%$ of the variation in market shares respectively. Similarly, in the mayonnaise industry, market and retailer effects explain $85 \%$ and $5 \%$ of the share variation respectively. For a few of the smaller industries, retailer effects are larger due to the fact that not all retailers carry them (e.g. refrigerated pasta) or that private labels are strong in some chains and not others. Across all industries, the retail component accounts for $20 \%$ of share variation, on average, whereas the market component accounts for more than $51 \%$. For this reason, it seems unlikely that the geographic patterns we observe in shares could be driven by retailer behavior.

To illustrate these findings, we focus on the retailer Albertsons, which has presence in the West and South regions of the United States. Albertsons' operations in the Denver and Los Angeles markets are sourced by the same buying office. Hence, the Albertsons data for these two markets reflect not only the same retailer, but also the same purchasing agent. In Figure 7, we plot the time series of the Kraft and Unilever brand shares in the mayonnaise industry, the two dominant products in the industry. On the left panels, we report the share history of each brand within Albertsons by market. On the right panels, we report the share history of each brand for the entire market (i.e. all retailers in the market) by market. In the graph, we can see that the market-specific component of the share histories is considerably more influential than 

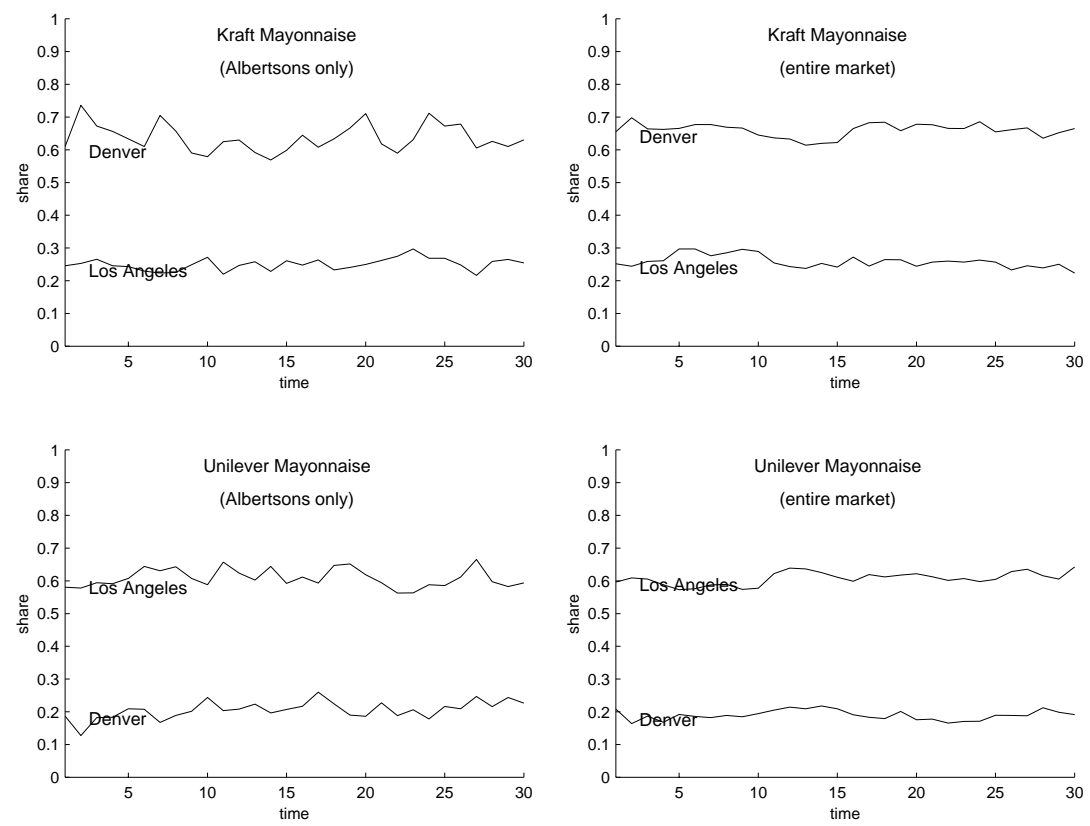

Figure 7: Brand shares in the mayonnaise industry with retailers and in markets

the retailer or time components. The within-Albertsons panels correspond very closely to the market-level results. Also, the week-to-week fluctuations in shares are extremely small relative to the cross-market fluctuations.

\section{D.3 Parent Company Effects}

Finally, we check whether the parent companies of the brands in our data may possess regional advantages that are passed-on to each of their brands. As before, we pool the within-market mean brand shares of the two top brands in each of the 31 industries and 50 geographic markets. From these 62 top brands, we then select each manufacturer owning at least 3 or more brands. These manufacturers include Conagra, Kraft, Sara Lee, Unilever, etc., and collectively account for the majority of the top brands in our data. Fixed-effects for each of these manufacturers collectively explain $11 \%$ of the variation in brand shares. The combination of the main manufacturer effects and interactions between manufacturers and markets, accounts for $17 \%$ of the share data. Hence, these results suggest that the extent to which manufacturers possess regional advantages is very small.

Overall, we conclude that none of these alternative explanations is capable of explaining the geographic patterns we observe in our brand shares. Furthermore, the entry effect appears to be robust, even after controlling for these various alternative firm asymmetries. 


\section{Conclusions}

We have documented several interesting patterns in the industrial market structures of CPG industries across US markets. The findings highlight the striking role of geography, an area that should be fruitful for future research with comparable marketing data. The results are suggestive of an important role for advertising in the formation of long-run industrial market structures both across CPG industries and across geographic areas. We observe an escalation in the level of advertising in larger markets. For those industries that advertise, the number of advertising brands appears to be independent of the size of the market. Hence, in larger markets we tend to see better (i.e. more heavily advertised) brands rather than more advertised brands. Finally, concentration levels for advertising intense industries appear to be bounded away from zero even in largest markets. These patterns in the data are consistent with the predictions of a model of Endogenous Sunk Costs (Shaked and Sutton 1987 and Sutton 1991).

In addition to the industry-level patterns, we also observe variation in the composition of market structures across markets. In most of our industries, we observe surprising amounts of dispersion across markets both in the leading brands' share levels and the identities of largestshare brands. Finally, we observe spatial dependence in brand shares in all 31 industries whereby a brand's share levels tend to be similar in neighboring markets. For two industries, we test for an early-mover effect on current shares. We find that early entry serves as a good predictor for both the levels and rank-orders of market shares for the top brands in a market. A comparable entry effect emerges for perceived brand quality, which is also consistent with the theory. In addition, we find that for the most of the brands studied, we observe a strong first-entry effect on advertising "share of voice." Finally, entry accounts for almost all of the spatial dependence in brand shares. Even though the entry effects can only be established for two industries, the patterns accounted for by entry are evident in almost all of the 31 industries in our sample. These findings are consistent with a theory in which first-entrants have a strategic advantage to secure high-quality and hence high-share (and high-profit) positions. Generalizing the entry effect in more industries and learning more about the sources of the entry effect will clearly be an interesting area for future research.

Ideally, collecting entry patterns for a broader set of CPG industries would allow us to test directly an additional implication of the theory. Mainly, for non-advertising intense industries, the entry effect should die-out as market size grows. In larger markets, non-advertising intense industries will tend to fragment, off-setting the potential benefits of early entry. ${ }^{33}$ With only two industries with entry information, it was not possible to test this additional implication.

\footnotetext{
${ }^{33}$ In a model of horizontal product differentiation, an early entrant could establish an advantage through its location choice (Lane 1980). However, as market size grows, this advantage would be offset as competitors gradually cover the entire horizontal continnum.
} 
We also consider several alternative explanations for the geographic patterns in our shares based on potential sources of firm asymmetry across markets. Proxies for several sources of firm heterogeneity, including geographic cost asymmetries (distance to plant) and relationships with retailers that could generate distributional advantages, do not appear to explain much of the geographic patterns in shares. Marketing variables such as promotions do not appear to covary with the geographic patterns in market shares. Instead, they appear to co-move with shares over time, within a market, a relatively small component of total share variation. As such, promotional awareness tactics do not appear to play a role in the formation of industrial market structure. This finding is in stark contrast with our results connecting media advertising and the geographic distribution of market shares. Establishing a robust causal relationship between advertising and market shares would require a more structural econometric model. Our current results are descriptive, and suggest that advertising co-moves with shares in the geographic dimension, the main source of share variation. Finally, we do observe a general tendency for large food companies owning multiple brands in the data to exhibit larger shares on average. However, we do not observe a regional advantage for any particular food company and, hence, the geographic patterns in shares do not appear to be the outcome of parent company operations.

Another interesting extension of the results would be to establish why the degree of advertising intensity varies across CPG industries. In the current paper, we use the advertising-to-sales ratio to measure advertising, which is based on equilibrium outcomes. A preferable approach would be to use a measure of the marginal effectiveness of advertising. An interesting direction for future research in this area would be to add more structure to the empirical analysis. Our current descriptive models help us identify evidence of a long-run effect of advertising on industrial market structure. However, the estimation of a structural demand system, by industry, could further enable one to measure the marginal effect of advertising on sales and to analyze the implications for equilibrium advertising levels in contrast with prices and promotions. Such an approach might also provide some insights into why CPG industries differ to such a degree in their advertising intensities.

Finally, our findings are consistent with the notion that advertising creates economies of scale that matter even in very large markets. This result obtains when advertising represents a fixed and sunk cost that raises consumer willingness-to-pay in a manner analogous to vertical product differentiation. Clearly, future research on the precise microeconomic role of advertising and how it might influence consumer willingness-to-pay in this manner would be of tremendous interest. 


\section{References}

[1] Advertising Age (1994), "Big G's Cereals Sag, Drag on Bottom Line," (July 4), 4.

[2] Alexander, D. (2003), "Food Industry Giants Spend Big Money for Prime Supermarket Shelf Space," Knight Ridder Tribune Business News, 1.

[3] Allison, R. J. and K. P. Uhl (1964), "Influence of Beer Brand Identification on Taste Perception," Journal of Marketing Research, vol 1, August, 36-39.

[4] Andras, T.L. and S.S. Srinivasan (2003), "Advertising Intensity and R\&D Intensity: Differences across industries and their impact on firm's performance," International Journal of Business and Economics, 2 (2), 167-76.

[5] Bagwell, K. (2003), "The Economic Analysis of Advertising," forthcoming in the Handbook of Industrial Organization, Vol. 3, eds. Robert Porter and Mark Armstrong.

[6] Bain, J.S. (1956), Barriers to New Competition, Cambridge, MA: Harvard University Press.

[7] Bernheim, B. Douglas and Michael D. Whinston (1990), "Multi-market Contact and Collusive Behavior," Rand Journal of Economics, vol 21:1 (Spring), 1-26.

[8] Berry S., and J. Waldfogel (2003), "Product Quality and Market Size," Wharton School, mimeo.

[9] Boatwright, Peter, Sanjay Dhar and Peter E. Rossi. (2004) "The Role of Retail Competition, Demographics and Account Retail Strategy as Drivers of Promotional Sensitivity," Quantitative Marketing and Economics, 2004, 2(2), pp. 169.

[10] Bresnahan T.S., and Peter Reiss (1991), "Entry and Competition in Concentrated Markets," Journal of Political Economy, vol. 95 (5), (October), pp. 977-1009

[11] Brown, C. L. and J. M. Lattin (1994), "Investigating the Relationship Between Time in Market and Pioneering Advantage," Management Science, 40(10), 1361-69.

[12] Campbell, J.R. and H.A. Hopenhayn (2004), "Market Size Matters," forthcoming in the Journal of Industrial Economics.

[13] Chakravarti, Amitav and Chris Janiszewski (2004), "The Influence of Generic Advertising on Brand Preferences," Journal of Consumer Research, 30 (March), 487-502.

[14] Comanor, W.S. and T.A. Wilson (1974), Advertising and Market Power, Cambridge, MA: Harvard University Press.

[15] — and Giorgio Topa (2002), "Socio-economic Distance and Spatial Patterns in Unemployment," Journal of Applied Econometrics, 17(4), 303-327.

[16] Cressie, Noel A.C. (1993), Statistics for Spatial Data, Wiley and Sons, New York, NY.

[17] Dekimpe, Marnik G. and Dominique M. Hanssens (1995), "Empirical Generalizations About Market Evolution and Stationarity," Marketing Science, 14 (Summer, part 2), G109-G121.

[18] Dhar, Sanjay K. and Stephen J. Hoch (1997), "Why Store Brand Penetration Varies by Retailer," Marketing Science, 16(3), pp. 208-27. 
[19] Dick, Astrid A. (2004), "Competition in Banking: Exogenous vs Endogenous Sunk Costs," Federal Reserve Bank New York, mimeo.

[20] Donnenfeld, S. and S. Weber (1995), "Limit Qualities and Entry Deterrence," The Rand Journal of Economics, 26, 113-130.

[21] Doraszelski, U. and S. Markovich (2004), "Advertising Dynamics and Competitive Advantage," Working Paper, Harvard University.

[22] D'Souza, Giles and Ram C. Rao (1995), "Can Repeating an Advertisement More Frequently Than the Competition Affect Brand Preference in a Mature Market?" Journal of Marketing, 59 (April), 32-42.

[23] Ellickson, Paul B. (2004a), "Does Sutton Apply to Supermarkets?" Duke University, mimeo.

[24] Ellickson, Paul B. (2004b), "Supermarkets as a Natural Oligopoly," Duke University, mimeo.

[25] Ellison, Glenn and Edward L. Glaeser (1997), "Geographic Concentration in U.S. Manufacturing Industries," Journal of Political Economy, 105:5, 889-927

[26] - and (1999), "The Geographic Concentration of Industry: Does Natural Advantage Explain Agglomoration," American Economic Review, 89:2, 311-316

[27] Federal Trade Commission (2001), "Report on the Federal Trade Commission Workshop on Slotting Allowances and Other Marketing Practices in the Grocery Industry," February, 72p.

[28] Gale Group (1993), Encyclopedia of Consumer Brands, Thompson-Gale

[29] Golder, Peter N. (2000), "Historical Method in Marketing Research with New Evidence on Long-Term Market Share Stability," Journal of Marketing Research, 37, 156-172.

[30] Golder, Peter N. and Gerard J. Tellis (1993), "Pioneer Advantage: Marketing Logic or Marketing Legend?" Journal of Marketing Research, 30 (May), 158-70

[31] Granger, Clive W. J. (1969), "Investigating causal relations by econometric models and crossspectral methods," Econometrica, 37, 424-438.

[32] Greenhut, John, M.L. Greenhut, and Sheng-Yung Li (1980), "Spatial Pricing Patterns in the United States," the Quarterly Journal of Economics, March, 329-350.

[33] Guadagni, Peter M. and John D.C. Little (1983), "A Logit Model of Brand Choice Calibrated on Scanner Data," Marketing Science, 2 (No. 3, Summer), 203-38

[34] Hamilton, James D. (1994), Time Series Analysis, Princeton University Press, Princeton, NJ.

[35] Heckman, James J. (1981), "The Incidental Parameters Problem and the Problem of Initial Conditions in Estimating A Discrete Time-Discrete Data Stochastic Process and Some Monte Carlo Evidence" in C. Manski and D. McFadden (eds.) Structural Analysis of Discrete Data With Econometric Applications, MIT Press, Cambrigde MA.

[36] Hoyer, Wayne D. and Steven P. Brown (1990), "Effects of Brand Awareness on Choice for a Common, Repeat-Purchase Product," Journal of Consumer Research, 17 (September), $141-48$. 
[37] Israilevich, Guillermo (2004), "Assessing Supermarket Product Line Decisions: The Impact from Slotting Fees," Quantitative Marketing and Economics, vol 2:2, p141-167

[38] Kalyanaram, Gurumurthy, W.T. Robinson, and G. Urban (1995), "Order of Market Entry: Established Empirical Generalizations, Emerging Generalizations, and Future Research" Marketing Science, 14:2 (part 2), 212-221

[39] Kardes, Frank R., and Gurumurthy Kalyanaram (1992), Order-of-Entry Effects onConsumer Memory and Judgment: An Information Integration Perspective, Journal of Marketing Research, 29, 343-357

[40] — - Murali Chandrashekaran, and Ronald J. Dornoff (1993), "Brand retrieval, consideration set composition, consumer choice, and the pioneering advantage," Journal of Consumer Research, 20 (1), 62-75

[41] Karnani, Aneel and Birger Wernerfelt (1985), "Multiple Point Competition," Strategic Management Journal, vol 6, 87-96

[42] Keller, K. L. (1987), " Memory Factors in Advertising: The Effect of Advertising Retrieval Cues on Brand Evaluations," Journal of Consumer Research, 14 (December), 316-33.

[43] Keller, K.L., Strategic Brand Management, (Prentice Hall, New Jersey: 2003).

[44] Kotler, P., Marketing Management (Prentice Hall, New Jersey: 2000).

[45] Krugman, Paul (1991), "Increasing Returns and Economic Geography," Journal of Political Economy, 99:3, 483-499

[46] Larsen Andras, Trina and Srini S. Srinivasan (2003), "Advertising Intensity and R\&D Intensity: Differences across Industries and Their Impact on Firms Performance," International Journal of Business and Economics, Vol. 2, No. 2, 167-176

[47] Lehmann-Grube, U. (1997), "Strategic Choice of Quality When Quality is Costly: The Persistence of the High Quality Advantage," The Rand Journal of Economics, 28 (2), 372-84.

[48] Mazzeo, Michael J. and Andrew M. Cohen (2004), "Market Structure and Competition among Retail Depository Institutions," Northwestern University, mimeo

[49] Nedungadi, Prakash (1990), "Recall and Consumer Consideration Sets: Influencing Choice Without Altering Brand Evaluations," Journal of Consumer Research, 17 (3), 263-76.

[50] Mark Pendergast (1999), Uncommon Grounds: The History of Coffee and How It Transformed Our World, Basic Books: New York, NY

[51] Robinson, W.T. and J. Chiang (1996), "Are Sutton's Predictions Robust?: Empirical Insights Into Advertising, R\&D, and Concentration," Journal of Industrial Economics, 44, 389-408

[52] Schmalensee, R. (1982), "Product Differentiation Advantages for Pioneering Brands," The American Economic Review, 72, 349-65.

[53] Shaked, A., and J. Sutton (1983) "Natural Oligopolies," Econometrica, 51(5), 1469-1483

[54] — , and (1987), "Product Differentiation and Industrial Structure," Journal of Industrial Economics, 36, 131-146 
[55] Smith, R.L. (1994), "Nonregular Regression," Biometrika, 81, 173-83.

[56] Sudhir, K. and V.R. Rao (2004), "Are Slotting Allowances Efficiency-Enhancing or AntiCompetitive?" Working Paper, Yale University.

[57] Sutton, J. (1991), Sunk Costs and Market Structure, Price Competition, Advertising, and the Evolution of Concentration, MIT Press, Cambrigde, MA.

[58] Sutton, J. (2003), "Market Structure - The Bounds Approach," forthcoming in the Handbook of Industrial Organization, Vol. 3, eds. Robert Porter and Mark Armstrong.

[59] Telser,L.G. (1964), "Advertising and Competition," Journal of Political Economy, 72 (6), $537-62$.

[60] Wilson, T.C. (1965), A Chronological Review of Hills Bros. Coffee, Inc., Presentation to Foote, Cone \& Belding. National Museum of American History, Washington, DC. 


\section{A Theoretical Framework}

This Appendix briefly outlines the technical details of the model and results from Shaked and Sutton (1987) and Sutton (1991). Consider a discrete choice model of consumer demand with both horizontal and vertical product differentiation. Define a product $x$ with characteristics $(\psi, \eta)$ where $\psi$ is vertical and $\eta$ is horizontal. Assume a consumer $h$ is described by his income, $Y_{h}$, where $Y_{h} \sim f(Y, \alpha)$, and an ideal point in horizontal product attribute space, $\alpha_{h}$. If consumer $h$ chooses brand $x$, he obtains utility:

$$
\begin{aligned}
U(x) & =u\left(\psi,\left|\omega-\alpha_{h}\right|, Y_{h}-p\right) \\
& =u\left(\psi, d, y_{h}\right)
\end{aligned}
$$

where $u_{\psi}>0, u_{d}<0, u_{\psi y}>0$ and $u_{y}$ and $\left|u_{d}\right|$ are bounded above. This model is sufficiently general to include many of the popular empirical models used in the brand choice literature such as the random coefficients multinomial logit and probit.

Firms play the following three-stage game. In the first stage, they decide whether or not to enter a market. In the second stage, they pick product attribute levels $(\psi, \eta)$ at cost $F(\psi)$ where

$F$ is strictly positive and increasing in the level of quality, $\psi$, and $\frac{F^{\prime}}{F}$ is bounded above. This latter assumption ensures that as quality levels increase, the incremental costs to raise quality do not become arbitrarily large. In the third stage, firms play a Bertrand pricing game conditional on the product attributes and marginal costs $c(\psi)$, where $c(\psi)<\bar{Y}<\max \left(Y_{h}\right)$. These assumptions imply that higher quality firms also have higher marginal costs. However, marginal costs are bounded above by some income level below the maximum income level and, hence, there will always be some consumers willing to pay for arbitrarily large quality levels. In other words, costs increase more slowly than the marginal valuation of the "highest-income" consumer.

The following propositions are proved in Shaked and Sutton (1987).

Proposition 1 If $u_{\psi}=0$ (i.e. no vertical differentiation), then for any $\varepsilon>0$, there exists a number of consumers $S^{*}$ such that for any $S>S^{*}$, every firm has an equilibrium market share less than $\varepsilon$.

This proposition captures the fact that, even with horizontal product differentiation, concentration falls in large markets because the economies of scale from the constant entry costs cease to matter.

When $u_{\psi}>0$, the following proposition holds:

Proposition 2 There exists an $\varepsilon>0$ such that at equilibrium, at least one firm has a market share larger than $\varepsilon$, irrespective of the market size.

This proposition captures the fact that when a fixed and sunk advertising cost can raise consumer willingness-to-pay, then advertising generates economies of scale that matter even in very large markets. As a result, entry is limited and markets remain concentrated.

\section{B Historic Evolution of Two Industries}

We now provide some details about two industries to highlight the relevance of the theory: coffee and mayonnaise, for which we were able to collect entry data. We indicate that (1) historically, the dominant brands in each category originated as regional brands; (2) advertising during local launch of these brands was very intense and costly; and (3) local leadership has persisted in absence of major innovations. 
The coffee industry The branded ground coffee industry has a long history in the United States (see e.g., Pendergast 1999). All of the current large national coffee brands originated as local brands in different geographic areas between 1848 and 1900. During this early period, firms relied heavily on advertising to build local market share. ${ }^{34}$

Folgers, currently the largest national brand, launched in San Francisco in 1848 and expanded from its San Francisco base eastward. It opened a plant in Kansas City in 1905. Folgers arrived in Chicago by 1959 (30 years after Hills Bros and Maxwell House). There it could not secure a better position than the 3rd spot in the market after Hills Bros and Maxwell House, suggesting that the quality reputation of the two latter firms had become hard to encroach upon. Upon acquisition by Procter and Gamble, Folgers became subject to a consent decree by the Federal Trade Commission to halt further expansion until 1971. Folgers therefore only became truly national in 1978, when it entered the New England markets.

The second largest national brand, Maxwell House, was launched in Nashville around 1892. Maxwell House first entered the markets in the southern and south-Atlantic states. Next, in 1921 they entered the New England markets, followed by the western and mid-western markets in 1924 and 1927 respectively. It was the first coffee brand to have national distribution and relied heavily on advertising during local introduction of their brand (the Gale Group, 1999).

Hills Bros is the third largest national coffee brand. It is was launched in 1881 from San Francisco and expanded eastward in the 1920's. It was the first firm to pioneer the use of vacuum packed cans in 1900, an innovation that the rest of the industry was slow to follow. By 1926, Hills Brothers was spending a quarter of a million dollars on advertising (most of it in Western states). It entered the Chicago market in 1930 with an unusually intense marketing campaign including heavy advertising and mailing all Chicago telephone subscribers a half-pound can of vacuum packed Hills Bros Coffee (Pendergast 1999). ${ }^{35}$ It dominates the Chicago market to this day.

Subsequent innovations in the category, such as the "keyless can" were far less impactful. The vacuum packed can represents the most substantial innovation in the industry during the 20th century. It was adopted by most large competitors by the 1920s and 1930s and remains in use as a standard today.

The mayonnaise industry The mayonnaise industry has traditionally been dominated by few manufacturers. Hellmann's introduced mayonnaise to a mass market on the East Coast in 1912, while Best Foods took the West Coast. Both firms subsequently expanded their trade territories land inward. Best Foods acquired Hellmann's in 1932, but the Hellmann's brand name was maintained in its trade territories. Best Foods was subsequently acquired by Unilever who nowadays informs its customers that "Best Foods is known as Hellmann's east of the Rockies." 36 In this respect, this particular pair of brands constitute an outlier in our database. Since they are co-managed, but never co-exist in any one market, we therefore aggregate them and treat them as a single brand called "Unilever."

Kraft Foods is another major competitor in the mayonnaise industry. Its brands are Kraft Real Mayonnaise and Kraft Miracle Whip. Miracle Whip was a major innovation for Kraft in 1933 after it realized that sales of its mayonnaise were slipping and that it needed a lower priced alternative to mayonnaise in the depression years. During the introduction of Miracle Whip,

\footnotetext{
${ }^{34}$ The historical ubiquity of advertising is evidenced by a newspaper article that noted that unadvertised products were "the genesis of unsuccessful merchandising" during the early stages of the branded coffee industry (Pendergast 1999).

${ }^{35}$ The Chicago market up until that time had been a fragmented market with approximately 50 local brands of which only three had more than $25 \%$ city-wide distribution (Wilson, 1965).

${ }^{36}$ See for instance http: \\www.mayo.com or http: \\www.hellmanns.com. Hellmann's and Best Foods have the exact same ingredients and in the same quantity order. The two brands are additionally manufactured at the same plant.
} 
Kraft "launched one of the biggest food advertising campaigns [...] and this initial effort led to 22 weeks of almost non-stop advertising, including a weekly two hour radio show." ${ }^{37}$ Thus, as with the coffee brands, advertising investment was high during launch. Despite its late arrival on the market, we hypothesize that Miracle Whip was effectively a substantial innovation for a sizeable segment of consumers. That is, Kraft was able to make Miracle Whip a "new entrant" to consumers because to some it provided a new and to others a better product.

Two smaller manufacturers also have a long history in this category. First, Duke's Mayonnaise was a first mover in South Carolina and was acquired by C.F. Sauer in 1929. The latter still sells the Duke's brand in the Carolina markets. Finally, Blue Plate Mayonnaise is the first major mayonnaise brand in the New Orleans market in 1927, and it still leads in this market.

After the introduction of Miracle Whip, new product innovation in the category has not been very frequent and has met with limited success. The most successful innovations in the category were the introduction of light and cholesterol free mayonnaise in the mid eighties by the incumbent manufacturers. Regular mayonnaise, which remains the bulk of category volume, has remained largely unchanged in appearance and taste since the popularization of the aforementioned brands in the twenties and thirties.

Discussion Historically, most large national CPG brands evolved from regional brands. These regional brands used advertising as a means to enhance their quality image in existing markets. All large national brands today initially launched with large-scale local advertising campaigns. Interestingly, while major shifts in local market shares do not occur in the coffee and mayonnaise categories, there are cases where later entrants (e.g., Folgers in New England) try hard to break into new markets. In such cases, the early entrants generally sustain a strong market share advantage. This suggests that the strategic first mover advantage, which initially is based on pre-emption through advertising investments later is also supported by accumulated advertising investments.

The current market structures (assortment of brands and relative shares) in both the coffee and mayonnaise industries have been in place for a long time. Neither of these categories has seen major successful innovations in the last decennia. An interesting issue is how one defines initial conditions in an industry. The theory we present looks at the product entry date. However, one might consider whether initial conditions can be re-formulated during periods of important product innovation. That is, one might consider comparing the date of product launch versus the date of launch of a radical innovation as two alternative definitions of "entry."

\footnotetext{
${ }^{37}$ See http: \\www.kraftcanada.com.
} 


\section{Additional Tables}

\begin{tabular}{|l|l|}
\hline Industry Groupings & $\begin{array}{l}\text { Bread and Bakery, Candy and Gum, Dairy Products, Frozen Entrees and Side } \\
\text { Dishes, Frozen and Refrigerated Desserts, Non-alcoholic Beverages, Packaged Dry } \\
\text { Groceries, Processed Canned and Bottled Foods, Refrigerated Meats }\end{array}$ \\
\hline Markets & $\begin{array}{l}\text { Albany, Atlanta, Baltimore, Birmingham, Boston, Buffalo, Charlotte, Chicago, } \\
\text { Cincinnati, Cleveland, Columbus, Dallas, Denver, Detroit, Des Moines, Grand } \\
\text { Rapids, Harrisburg, Houston, Indianapolis, Jacksonville, Kansas City, Los Angeles, } \\
\text { Louisville, Little Rock, Memphis, Miami, Milwaukee, Minneapolis, Nashville, New } \\
\text { Orleans/Mobile, New York, Oklahoma City/Tulsa, Omaha, Orlando, Philadelphia, } \\
\text { Phoenix, Pittsburg, Portland, Raleigh/Durham, Richmond/Norfolk, Sacramento, } \\
\text { San Antonio, San Diego, Seattle, San Francisco, St. Louis, Syracuse, Tampa, Wash- } \\
\text { ington }\end{array}$ \\
\hline $\begin{array}{l}\text { A \& P, Super Fresh, ABCO, ACME, Albertson's, Almac's, AWG, BiLo, Big Bear, } \\
\text { Bruno's, Del Champs, Demoulas Market Basket, Dominick's, Eagle Food Centers, } \\
\text { Farm Fresh, Farmer Jack, Fiesta Mart Inc., Food4Less, Food Lion, Food Mart, Fred } \\
\text { Meyer, Gerland's, Giant, Giant Eagle, Grand Union, Great American, H.E.B., Har- } \\
\text { ris Teeter, Harvest Foods, Homeland Food Stores, Hughes Market, Hy Vee Foods, } \\
\text { Jewel Food Stores, Kash N Karry, King Soopers, Kohl's, Lucky, Lucky Stores, Min- } \\
\text { yard Food Stores, National, Omni, P\&C, Pathmark, Publix, Purity Markets, Ra- } \\
\text { ley's, Ralphs, Randall's, Riser Foods Inc., Safeway, Save Mart, Schnuck's, Schweg- } \\
\text { mann, Sentry Markets, Shaw's, Shoprite, Smith's Food and Drug Centers, Smitty's, } \\
\text { Star Market, Stop and Shop, Super Fresh, Kroger, Tom Thumb, Tops Markets, } \\
\text { Vons, Waldbaum's, Wegman's Food Markets, Winn Dixie }\end{array}$ \\
\hline
\end{tabular}

${ }^{a}$ We classify the 31 industries into 9 groupings

Table C.I: The structure of the data set 


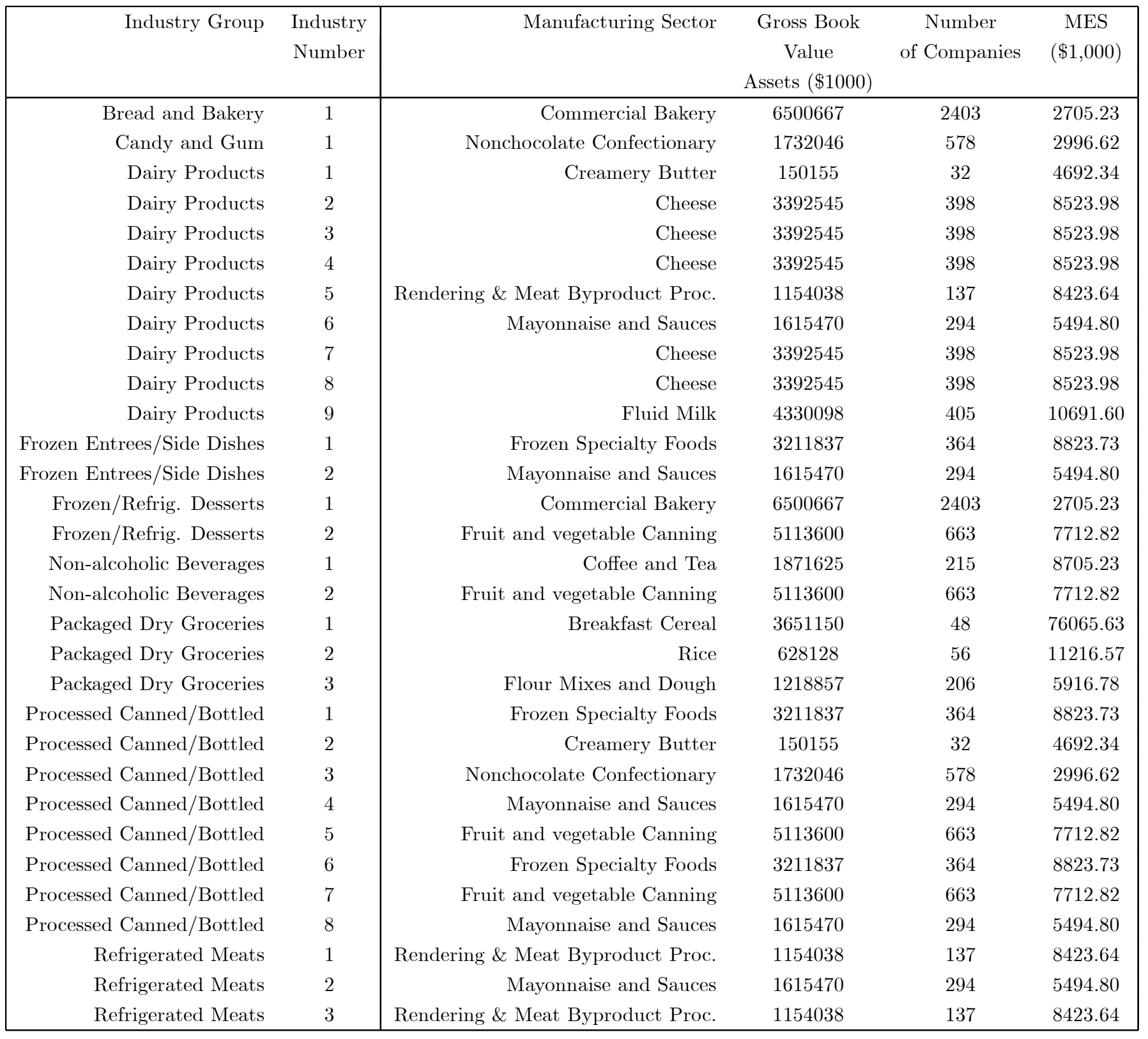

Table C.II: 1997 Economic Census Data used to proxy for Minimum Efficient Scale for a subset of our industries. 


\begin{tabular}{|c|c|c|c|c|c|}
\hline Industry Group & Industry Number & mean C1 & std C1 & $\min \mathrm{C} 1$ & $\max \mathrm{C} 1$ \\
\hline Bread and Bakery & 1 & 0.13 & 0.06 & 0.05 & 0.31 \\
\hline Candy and Gum & 1 & 0.32 & 0.08 & 0.12 & 0.49 \\
\hline Dairy Products & 1 & 0.37 & 0.12 & 0.06 & 0.61 \\
\hline Dairy Products & 2 & 0.26 & 0.10 & 0.11 & 0.53 \\
\hline Dairy Products & 3 & 0.65 & 0.07 & 0.51 & 0.78 \\
\hline Dairy Products & 4 & 0.28 & 0.13 & 0.06 & 0.67 \\
\hline Dairy Products & 5 & 0.26 & 0.10 & 0.11 & 0.59 \\
\hline Dairy Products & 6 & 0.57 & 0.14 & 0.31 & 0.77 \\
\hline Dairy Products & 7 & 0.26 & 0.07 & 0.15 & 0.40 \\
\hline Dairy Products & 8 & 0.45 & 0.17 & 0.22 & 0.94 \\
\hline Dairy Products & 9 & 0.33 & 0.08 & 0.19 & 0.60 \\
\hline Frozen Entrees/Side Dishes & 1 & 0.20 & 0.05 & 0.12 & 0.32 \\
\hline Frozen Entrees/Side Dishes & 2 & 0.37 & 0.08 & 0.22 & 0.57 \\
\hline Frozen/Refrigerated Desserts & 1 & 0.56 & 0.15 & 0.21 & 0.79 \\
\hline Frozen/Refrigerated Desserts & 2 & 0.32 & 0.09 & 0.15 & 0.63 \\
\hline Non-alcoholic Beverages & 1 & 0.37 & 0.07 & 0.25 & 0.57 \\
\hline Non-alcoholic Beverages & 2 & 0.22 & 0.06 & 0.15 & 0.37 \\
\hline Packaged Dry Groceries & 1 & 0.33 & 0.05 & 0.24 & 0.43 \\
\hline Packaged Dry Groceries & 2 & 0.25 & 0.06 & 0.12 & 0.39 \\
\hline Packaged Dry Groceries & 3 & 0.57 & 0.12 & 0.33 & 0.87 \\
\hline Processed Canned/Bottled Foods & 1 & 0.55 & 0.06 & 0.42 & 0.69 \\
\hline Processed Canned/Bottled Foods & 2 & 0.20 & 0.04 & 0.13 & 0.32 \\
\hline Processed Canned/Bottled Foods & 3 & 0.48 & 0.08 & 0.24 & 0.67 \\
\hline Processed Canned/Bottled Foods & 4 & 0.32 & 0.07 & 0.19 & 0.45 \\
\hline Processed Canned/Bottled Foods & 5 & 0.36 & 0.11 & 0.19 & 0.69 \\
\hline Processed Canned/Bottled Foods & 6 & 0.48 & 0.14 & 0.23 & 0.76 \\
\hline Processed Canned/Bottled Foods & 7 & 0.53 & 0.16 & 0.30 & 0.90 \\
\hline Processed Canned/Bottled Foods & 8 & 0.23 & 0.10 & 0.11 & 0.43 \\
\hline Refrigerated Meats & 1 & 0.31 & 0.11 & 0.14 & 0.63 \\
\hline Refrigerated Meats & 2 & 0.31 & 0.14 & 0.11 & 0.78 \\
\hline Refrigerated Meats & 3 & 0.22 & 0.09 & 0.12 & 0.50 \\
\hline
\end{tabular}

Table C.III: One Firm Concentration statistics for a subset of the 31 industries $(N=50$ markets $)$ 


\begin{tabular}{|c|c|c|c|}
\hline \multirow[t]{2}{*}{ Industry Group } & \multirow[t]{2}{*}{ Industry Number } & \multicolumn{2}{|c|}{ Spatial Correlation $^{c}(\widehat{\rho})$} \\
\hline & & At 0 distance & Average $0-600 \mathrm{M}$ distance \\
\hline Bread and Bakery & 1 & 0.25 & -0.02 \\
\hline Candy and Gum & 1 & 0.65 & 0.21 \\
\hline Dairy Products & 1 & 0.48 & 0.31 \\
\hline Dairy Products & 2 & 0.93 & 0.36 \\
\hline Dairy Products & 3 & 0.54 & 0.03 \\
\hline Dairy Products & 4 & 0.63 & 0.10 \\
\hline Dairy Products & 5 & 0.34 & 0.05 \\
\hline Dairy Products & 6 & 0.87 & 0.31 \\
\hline Dairy Products & 7 & 0.53 & 0.16 \\
\hline Dairy Products & 8 & 0.56 & 0.11 \\
\hline Dairy Products & 9 & 0.58 & 0.15 \\
\hline Frozen Entrees/Side Dishes & 1 & 0.64 & 0.26 \\
\hline Frozen Entrees/Side Dishes & 2 & 0.65 & 0.16 \\
\hline Frozen/Refrigerated Desserts & 1 & 0.52 & 0.18 \\
\hline Frozen/Refrigerated Desserts & 2 & 0.85 & 0.15 \\
\hline Non-alcoholic Beverages & 1 & 0.77 & 0.42 \\
\hline Non-alcoholic Beverages & 2 & 0.69 & 0.30 \\
\hline Packaged Dry Groceries & 1 & 0.56 & 0.33 \\
\hline Packaged Dry Groceries & 2 & 0.62 & 0.35 \\
\hline Packaged Dry Groceries & 3 & 0.52 & 0.25 \\
\hline Processed Canned/Bottled Foods & 1 & 0.57 & 0.17 \\
\hline Processed Canned/Bottled Foods & 2 & 0.46 & 0.21 \\
\hline Processed Canned/Bottled Foods & 3 & 0.73 & 0.12 \\
\hline Processed Canned/Bottled Foods & 4 & 0.92 & 0.18 \\
\hline Processed Canned/Bottled Foods & 5 & 0.38 & 0.08 \\
\hline Processed Canned/Bottled Foods & 6 & 0.51 & 0.26 \\
\hline Processed Canned/Bottled Foods & 7 & 0.80 & 0.32 \\
\hline Processed Canned/Bottled Foods & 8 & 0.46 & 0.35 \\
\hline Refrigerated Meats & 1 & 0.58 & 0.30 \\
\hline Refrigerated Meats & 2 & 0.48 & 0.12 \\
\hline Refrigerated Meats & 3 & 0.44 & 0.11 \\
\hline \multicolumn{2}{|c|}{ Average across 31 industries } & 0.60 & 0.21 \\
\hline \multicolumn{4}{|c|}{$\begin{array}{l}{ }^{a} \mathrm{R}^{2} \text { reported } \\
b_{\text {average }} \mathrm{R}^{2} \text { across the two top selling national brands } \\
c_{\text {average spatial correlation across the two top selling national brands }}\end{array}$} \\
\hline
\end{tabular}

Table C.IV: Spatial description of a subset of the 31 industries. 


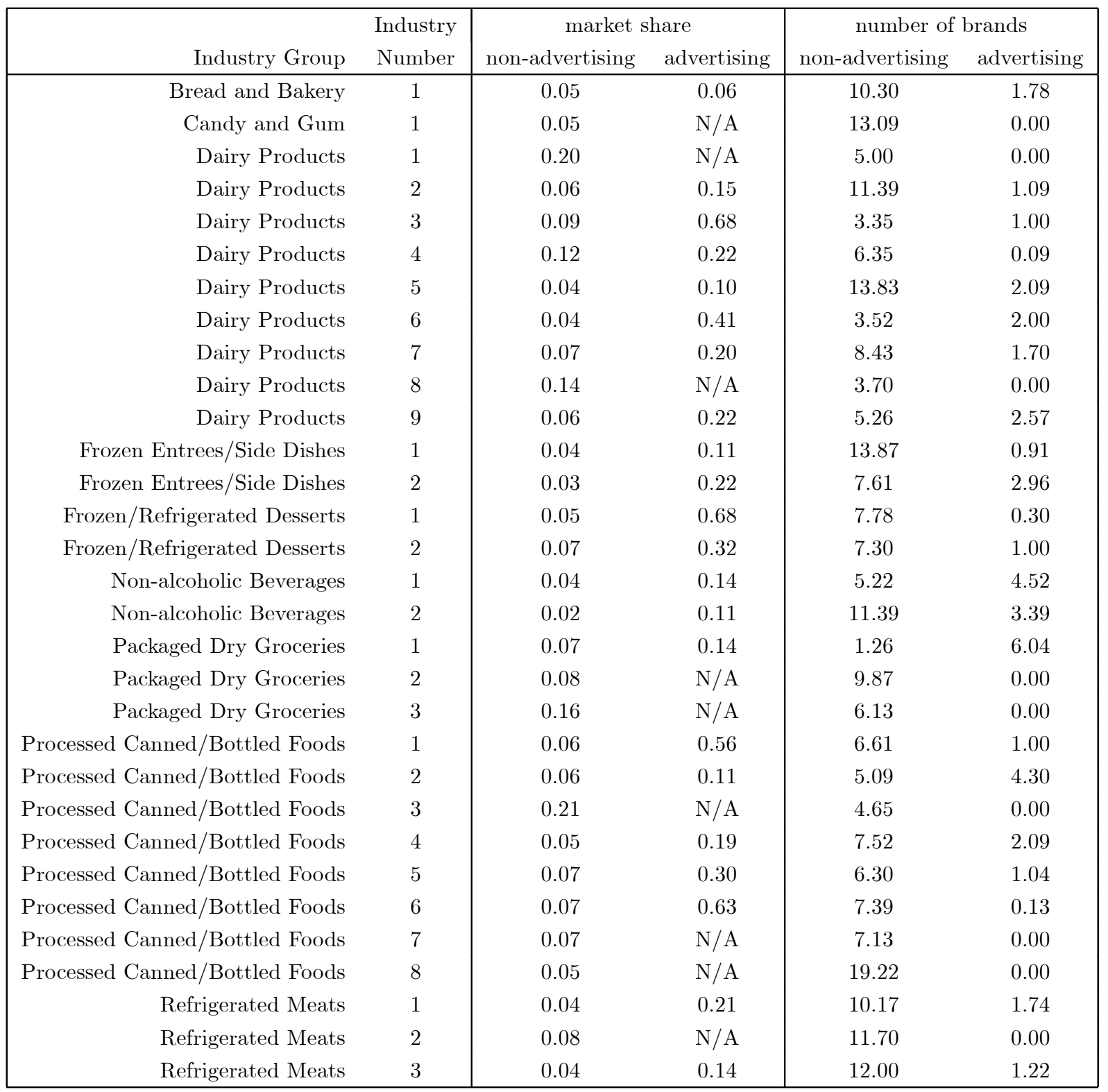

Table C.V: Summary of advertising versus non-advertising brands by industry across a subset of the 31 industries. For each industry, we report the mean across geographic markets. 